Research Paper

\title{
Neuroimmunological characterization of a mouse model of primary progressive experimental autoimmune encephalomyelitis and effects of immunosuppressive or neuroprotective strategies on disease evolution
}

\author{
Daniela Buonvicino $^{\mathrm{a}, *}$, Giuseppe Ranieri ${ }^{\mathrm{a}}$, Sara Pratesi ${ }^{\mathrm{b}}$, Daniele Guasti ${ }^{\mathrm{c}}$, Alberto Chiarugi ${ }^{\mathrm{a}}$ \\ ${ }^{a}$ Department of Health Sciences, Section of Clinical Pharmacology and Oncology, University of Florence, Florence, Italy \\ ${ }^{\mathrm{b}}$ Centre of Immunological Research DENOTHE, Department of Experimental and Clinical Medicine, University of Florence, Florence, Italy \\ ${ }^{\mathrm{c}}$ Department of Clinical and Experimental Medicine, Research Unit of Histology \& Embryology, University of Florence, Florence, Italy
}

\section{A R T I C L E I N F O}

\section{Keywords:}

Progressive EAE

Neurodegeneration

Epitope spreading

Dexamethasone

Mitochondria

Bioenergetics

Bezafibrate

Biotin

\begin{abstract}
A B S T R A C T
Progressive multiple sclerosis (PMS) is a devastating disorder sustained by neuroimmune interactions still wait to be identified. Recently, immune-independent, neural bioenergetic derangements have been hypothesized as causative of neurodegeneration in PMS patients. To gather information on the immune and neurodegenerative components during PMS, in the present study we investigated the molecular and cellular events occurring in a Non-obese diabetic (NOD) mouse model of experimental autoimmune encephalomyelitis (EAE). In these mice, we also evaluated the effects of clinically-relevant immunosuppressive (dexamethasone) or bioenergetic drugs (bezafibrate and biotin) on functional, immune and neuropathological parameters. We found that immunized NOD mice progressively accumulated disability and severe neurodegeneration in the spinal cord. Unexpectedly, although CD4 and CD8 lymphocytes but not B or NK cells infiltrate the spinal cord linearly with time, their suppression by different dexamethasone treatment schedules did not affect disease progression. Also, the spreading of the autoimmune response towards additional immunogenic myelin antigen occurred neither in the periphery nor in the CNS of EAE mice. Conversely, we found that altered mitochondrial morphology, reduced contents of mtDNA and decreased transcript levels for respiratory complex subunits occurred at early disease stages and preceded axonal degeneration within spinal cord columns. However, the mitochondria boosting drugs, bezafibrate and biotin, were unable to reduce disability progression. Data suggest that EAE NOD mice recapitulate some features of PMS. Also, by showing that bezafibrate or biotin do not affect progression in NOD mice, our study suggests that this model can be harnessed to anticipate experimental information of relevance to innovative treatments of PMS.
\end{abstract}

\section{Introduction}

In spite of the remarkable advancement in the therapeutic armamentarium available to counteract multiple sclerosis (MS) in its relapsing-remitting phase, there is still a high need for drugs able to prevent and/or delay disability worsening in patients affected by primary or secondary progressive MS (Ciotti and Cross, 2018; Ontaneda and Fox, 2015). Indeed, even the positive results recently obtained in clinical trials with ocrelizumab (a B cell-depleting anti CD20 antibody) in patients with primary progressive MS (PPMS) and with siponimod (a selective shingosine- 1 and -5 phosphate receptor agonist) in those presenting secondary progressive MS (SPMS) are quantitatively limited and might be restricted to specific subgroups of MS patients (i.e. short progression history and substantial CNS inflammatory activity) (Kappos et al., 2018; Montalban et al., 2017). In keeping with this, the causative link between the different types of neuroimmune infiltrates and development of disease progression is a topic that continues to be highly debated (Lassmann, 2018). From a pathophysiological point of view, it makes sense that neurodegenerative events responsible for progression might be triggered by repetitive cycles of demyelination sustained by the autoimmune infiltrates (Bjartmar et al., 2003). However, the inability of immunosuppressive drugs to counteract disease progression (Baldassari and Fox, 2018) suggest a more complex scenario where an immune-independent component contribute to neurodegeneration (Lee et al., 2014). The identification of neuroprotective strategies able to counteract axonal loss might synergize with existing

\footnotetext{
*Corresponding author at: Department of Health Sciences, Section of Clinical Pharmacology and Oncology, University of Florence, Viale Pieraccini 6, 50139 Firenze, Italy.

E-mail address: daniela.buonvicino@unifi.it (D. Buonvicino).
} 
immunomodulatory therapies to improve efficacy of progressive MS treatment.

On this basis, a great deal of effort has been focused at elucidating the pathogenetic mechanisms underlying neurodegeneration during MS progression at the cellular and molecular level. There is large consensus that disability worsening is due to accumulating axonal loss within both the spinal cord and brain (Bjartmar et al., 2000; Trapp et al., 1998). Although the precise molecular mechanisms of neurodegeneration are not without contention (Witte et al., 2019), it has been proposed that a sort of "virtual hypoxia" promoted by chronic demyelination and derangement of mitochondrial bioenergetics is the main perpetrator of axonal degeneration (Sedel et al., 2016; Trapp and Stys, 2009). Specifically, demyelinated axons undergo derangement of sodium homeostasis that on the one hand increases adenosine triphosphate (ATP) consumption by the $\mathrm{Na}^{+} / \mathrm{K}^{+}$ATPase, and on the other prompts inversion of the $\mathrm{Na}^{+} / \mathrm{Ca}^{2+}$ transporter and intracellular $\mathrm{Ca}^{2+}$ overload. The latter further compromises axonal energy dynamic, eventually leading to oncotic swelling and degeneration (Sedel et al., 2016). Remarkably, impaired mitochondrial respiration, typically identified in normal appearing white and gray matter of MS patients (Witte et al., 2013a), further worsens axonal energy failure. On this basis, there is large consensus that support of energy dynamics within both demyelinated and healthy CNS regions may represent a key strategy for therapeutic intervention during disease progression (Witte et al., 2013a). However, with the possible exception of biotin (Sedel et al., 2016), such an approach did not lead to any drug candidate with realistic translational potential to PMS therapy, so far.

With this information in mind, in order to define the therapeutic potential of mitochondrial active compounds to treatment on MS progression, we adopted a bedside to bench strategy. Basically, in an animal model of progressive experimental autoimmune encephalomyelitis (EAE) we planned to test approved drugs known to support cellular bioenergetics that might be readily translated to treatment of PMS. We hypothesized that such a repurposing approach on the one hand could corroborate the relevance of mitochondria as therapeutic targets for PMS treatment, and on the other might accelerate clinical translation.

In this study, we first evaluated several immune and neuropathological parameters of NOD mice with EAE in order to find possible similarities with PMS. In these animals, we then studied the effects of two mitochondrially-active drugs such as bezafibrate, able to promote mitochondriogenesis and organelle functioning by activating the peroxisome proliferator-activated receptor (PPAR) $\gamma$ coactivator-1 $\alpha$ (PGC-1 $\alpha$ ) axis, and biotin, a well-known vitamin currently evaluated in clinical trials for PMS therapy but, surprisingly, never tested in EAE models.

\section{Materials and methods}

\subsection{Experimental design}

All animal care and experimental procedures were performed according to the European Community guidelines for animal care (European Communities Council Directive 2010/63/EU) and were approved by the Committee for Animal Care and Experimental Use of the University of Florence. Female NOD/ShiLtj (6, 8 and 10 week old) purchased from Charles River (Milan, Italy) were housed in a conventional unit (5-6 per cage) with free access to food (Harlan Global Diet 2018, Harlan Laboratories, Udine, Italy) and water, and maintained on a $12 \mathrm{~h} \mathrm{light/dark} \mathrm{cycle} \mathrm{at} 21^{\circ} \mathrm{C}$ room temperature.

\subsection{EAE induction and treatment}

EAE was induced in NOD/ShiLtj mice by subcutaneous immunization, with $250 \mu \mathrm{g}$ of $\mathrm{MOG}_{35-55}$ peptide (synthesized by EspiKem Srl., University of Florence, Italy), emulsified in complete Freund's adjuvant (CFA) (Sigma, Milan, Italy) containing $4 \mathrm{mg} / \mathrm{ml}$ of Mycobacterium tuberculosis H37RA (Difco Laboratories, Detroit, MI, USA) in the flanks and at the base of the tail. Immediately thereafter and $48 \mathrm{~h}$ later, mice received intraperitoneal injection (i.p.) of $200 \mathrm{ng}$ pertussis toxin (PTX) (Sigma, Milan, Italy) in $100 \mu$ l Phosphate-Buffered Saline (PBS). Clinical signs of EAE were examined daily by blinded operators. The following score were assigned: 0 , normal; 0.25 or 0.5 , splay reflex test (performed by lifting the mouse by its tail and observing the degree of hindlimb splay during $10 \mathrm{~s}$. If both hindlimbs were splayed outward away from the abdomen, a 0 score was assigned. If one or both hindlimbs were partially retracted toward the abdomen without touching it, a score 0.25 or 0.5 was assigned, respectively); 1 , weakness of the tail/hind limbs; 2, ataxia and/or difficulty in righting; 3, paralysis of the hind limbs and/or paresis of the forelimbs; 4, tetraplegia. Because of ethical reasons, score 4 mice were euthanized as soon as they reached the score. All the different treatments started at score 1. Bezafibrate and biotin (Sigma, Milan, Italy) were dissolved in PBS and administrated per os (oral somministration) on a daily basis at 100 and $50 \mathrm{mg} / \mathrm{kg}$ body weight, respectively. Dexamethasone (Sigma, Milan, Italy) was dissolved in PBS and administrated per os at $10 \mathrm{mg} / \mathrm{kg}$ for 5 days or daily at $0.3 \mathrm{mg} / \mathrm{kg}$ from score 1 . Immunized vehicle-treated animals daily received the same amount of PBS.

\subsection{Board test}

The board test consisted of a $40 \mathrm{~cm}$ square plane. Mice were placed on the center of the board one by one and allowed to move about freely. Two electric sensors, crossing the plane from midpoint to midpoint of opposite sides, thus dividing the plane into four equal quadrants, automatically signaled the movement of the animal on the surface of the plane. For each mouse is reported the total counts of spontaneous locomotion in $10 \mathrm{~min}$ (Galeotti et al., 2006).

\subsection{Flow cytometry}

Mononuclear spleen cells and spinal cord infiltrating leukocytes were characterized by flow cytometry. Briefly, MOG-immunized NOD mice were sacrificed at different disease score and perfused with cold saline prior to organ collection, then a single cell suspension for each sample was prepared (Cavone et al., 2011; Cavone et al., 2015) and stained with anti-CD4 FITC, anti-CD8 PE, anti-C45R (B220) APC and anti-NK 1.1 PerCP-Vio770 or isotype-matched control IgG antibodies (all from Miltenyi Biotec, Bergisch Gladbach, Germany) according to the manufacturer's instructions. The cells were then analyzed using a FACSCanto II flow cytometer (BD Biosciences) equipped with FACSDiva software (BD Biosciences), acquiring a total of $10^{4}$ events for spleen extracts and at least $10^{5}$ events for spinal cord extracts. 10 week-old NOD mice were used as control.

\subsection{Antigen-dependent T-cell proliferation and ELISA}

Cells extracted from lymph nodes, spleen or spinal cord of control or MOG $_{35-55}$-immunized mice were cultured in complete RPMI in 96 wells plates $\left(2 \times 10^{5}\right.$ cells per well) and stimulated or not with $50 \mathrm{ng} / \mathrm{ml}$ phorbol myristate acetate (PMA) plus $1 \mu \mathrm{g} / \mathrm{ml}$ ionomycin, $\mathrm{MOG}_{35-55}$ $(20 \mu \mathrm{g} / \mathrm{ml})$ or $\mathrm{MOG}_{8-22}(20 \mu \mathrm{g} / \mathrm{ml})$ (Cavone et al., 2015). After $72 \mathrm{~h}$, the proliferative response was measured by $\left[{ }^{3} \mathrm{H}\right]$ thymidine incorporation test. $\left[{ }^{3} \mathrm{H}\right]$ Thymidine ( $1 \mathrm{Ci}$ /well; PerkinElmer) was added and pulsed for the last $12 \mathrm{~h}$. Plates were then harvested (Tomtec MacIII) on glass fibre filter (PerkinElmer), and thymidine uptake was measured by liquid scintillation in a MicroBeta 1450 Trimux counter (Wallac). Supernatants were collected after $72 \mathrm{~h}$ of culture for IFN- $\gamma$ measurements by ELISA (Life technologies, Monza, Italy) according to the manufacturer's instructions. Detection limit for IFN- $\gamma$ was $5.3 \mathrm{pg} / \mathrm{ml}$.

\subsection{Plasma Ab ELISA}

Whole blood was collected via cardiac puncture from NOD mice at 
different time points after MOG 35-55 immunization. Samples were anticoagulated in $10 \mu \mathrm{l}$ of $50 \mathrm{mM}$ EDTA and centrifuged for $5 \mathrm{~min}$ at $500 \mathrm{rpm}$. Plasma was removed and frozen at $-80 \mathrm{oC}$ until assayed. MOG 35-55 peptide was diluted $(10 \mu \mathrm{g} / \mathrm{ml})$ in bicarbonate coating buffer ( $\mathrm{pH} 9.0)$, aliquoted (100 $\mu \mathrm{l} /$ well) into Maxisorb ${ }^{\circledR}$ immunoassay plates (Nunc/Thermo Fisher Scientific, Rochester, NY, USA) and incubated overnight at $4 \mathrm{oC}$. Plates were blocked for $2 \mathrm{~h}$ with $3 \% \mathrm{BSA} /$ PBS. After washing with PBST, plasma samples $(100 \mu \mathrm{l})$ diluted $1: 100$ or 1:400 in PBS-0.05\% Tween-20 were added to wells and incubated for $1 \mathrm{~h}$ at room temperature (RT). Wells were washed and incubated with HRP-labeled antibodies (Jackson ImmunoResearch, West Grove, PA, USA) versus IgG (diluted 1:40,000) in dilution buffer. Following $1 \mathrm{~h}$ incubation at RT, wells were washed and incubated with $100 \mu \mathrm{l} \mathrm{TMB}$ substrate solution (Sigma Aldrich) in the dark for $10 \mathrm{~min}$. The reaction was stopped with the addition of $100 \mu \mathrm{l} 2.5 \mathrm{~N} \mathrm{H} 2 \mathrm{SO} 4$ and the Abs450 was read using a Synergy microplate reader (Biotek, Winooski, VT, USA) (Liu et al., 2012).

\subsection{Histological analysis}

Lumbosacral spinal cord from control or MOG-immunized NOD mice at different times of disease were collected, fixed in $4 \%$ paraformaldehyde in $0.1 \mathrm{M}$ PBS, embedded in paraffin and cut into $10 \mu \mathrm{m}$ thin section. Axonal loss and myelin loss were assessed by Bielschowsky's silver staining and Luxol Fast Blue, respectively. Images were acquired by using an Olympus BX40 microscope (Olympus, Milan, Italy) and a digital camera (Olympus DP50) with NIS-Elements software; sections were analyzed by blinded operator by using ImageJ software (71 - Schneider CA).

\subsection{Quantitative PCR}

Genomic DNA was extracted from mice spinal cord with the NucleoSpin TriPrep kit (Macherey-Nagel, Duren, Germany). Total RNA from mouse spinal cord was isolated using Trizol Reagent (Life Technologies). One $\mu \mathrm{g}$ of RNA was retrotranscribed using iScript (BioRad, Milan, Italy). Real-Time PCR was performed using Rotor-Gene 3000 (Qiagen, Milan, Italy) and the Rotor-Gene TM SYBR ${ }^{\circledast}$ Green PCR Kit (Qiagen, Milan, Italy), the reactions were run at $95^{\circ} \mathrm{C}$ for $30 \mathrm{~s}, 95^{\circ} \mathrm{C}$ for $5 \mathrm{~s}$ and $60^{\circ} \mathrm{C}$ for $15 \mathrm{~s}$ for 45 cycles. Mitochondrial content was quantified by measuring the ratio between the mitochondrial $N d 1$ and nuclear $\beta$-actin gene amplification products (Felici et al., 2017). The following primers were used: for PGC1- $\alpha$ : forward 5'-GACAGATGGAG CCGTGACCACTG- $3^{\prime}$ and reverse $5^{\prime}$-CTGATCCTGTGGGTGTGGTTTGC3; for PPAR- $\alpha$ forward $5^{\prime}$-GGCTCTGTCATCACAGACACCCTCT-3' and reverse $5^{\prime}$-GCCGAATAGTTCGCCGAAAGAAGCCC-3'; for $m t-N d 2$ forward 5'-ATTATCCTCCTGGCCATCGTA- ${ }^{\prime}$ ' and reverse 5'-AAGTCCTAT GTGCAGTGGGAT-3'; for Ndufv2 forward $5^{\prime}$-GTGCACAATGGTGCTGG AGGAG-3' and reverse 5'-GGTAGCCATCCATTCTGCCTTTGG-3'; for Atp5d forward 5'-CAGCACGGGCTGAGATCCAGAT-3' and reverse 5'-GACAGGCACCAGGAAGCTTTAAGC-3'; for Cox 1 forward 5'- TATCA ATGGGAGCAGTGTTTG- $3^{\prime}$ and reverse $5^{\prime}$ - AGGCCCAGGAAATGTTGAG -3'; for Cox2 forward 5'- CTGAAGACGTCCTCCACTCAT 0-3' and reverse 5'- TCTAGGACAATGGGCATAAAG -3'; for Cox15 forward 5'- GTTCTG AGATGGGCACTGGACCA $-3^{\prime}$ and reverse $5^{\prime}$ - GGGGCACGTGTTCCTGA ATCTGT -3'; for $18 S$ forward 5'-AAAACCAACCCGGTGAGCTCCCTC-3' and reverse $5^{\prime}$-CTCAGGCTCCCTCTCCGGAATCG-3'; for $m t-N d 1$ forward 5'-TGCCAGCCTGACCCATAGCCATA-3' and reverse 5'-ATTCTCCTTCT GTCAGGTCGAAGGG-3'; for $\beta$-actin forward 5'-GCAGCCACATTCCCGC GGTGTAG-3' and reverse 5'-CCGGTTTGGACAAAGACCCAGAGG-3'.

\subsection{Transmission electron microscopy}

Transmission electron microscopy was performed as previously described (Felici et al., 2017). Briefly, spinal cord was fixed in Karnovsky's solution, post-fixed in $1 \%$ osmium tetroxide and embedded in
Epon 812. Ultrathin sections were stained with uranyl acetate and alkaline bismuth subnitrate and examined under a JEM 1010 electron microscope (Jeol, Tokyo, Japan) at $80 \mathrm{kV}$. Micrographs were taken at final magnifications of $15,000 \times$ and $80,000 \times$ using a MegaView III digital camera and interfacing software (SIS-Soft Imaging System, Munster, Germany). To analyze cristae area, only mitochondria unequivocally present within axoplasmic fields were analyzed. Areas of cristae were measured using iTEM image analysis software (SIS).

\subsection{ATP measurement}

Cellular ATP content was measured by means of an ATPlite kit based on the production of light caused by the reaction of ATP with added luciferase and D-luciferin (Perkin Elmer, Milan). Briefly, $70 \mu \mathrm{l}$ of luciferase buffer and then $20 \mu \mathrm{l}$ of D-luciferin was added to cells grown in a 48 well plate. Cell luminescence was evaluated after 5 min by means of a luminometer (Buonvicino et al., 2018).

\subsection{Neuronal cultures}

Pure neuronal cultures were prepared by seeding cortical cells obtained from 16 to 18 days old embryos as previously described (Chiarugi and Moskowitz, 2003). Neurons were cultured in NeurobasalTM medium with B-27 supplement (GIBCO) and $0.5 \mathrm{mM}$ glutamine onto 48 poly-D-lysine-coated (Sigma, Milan, Italy) multiwell plates. Neurons were plated at a density of $2 \times 10^{5}$ cells $\cdot \mathrm{ml}^{-1}$ and were used at 7 DIV from preparation.

\subsection{Primary oligodendrocyte cultures}

Purified cortical oligodendrocyte progenitor cell (OPC) cultures were prepared as described elsewhere (Fumagalli et al., 2011). Wistar rat pups (postnatal day 1) were killed and cortices removed, mechanically and enzymatically dissociated, suspended in DMEM con-

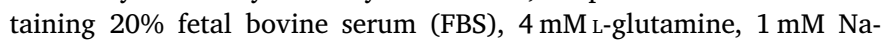
pyruvate, $100 \mathrm{U} / \mathrm{ml}$ penicillin, $100 \mathrm{U} / \mathrm{ml}$ streptomycin (EuroClone, Milan, Italy), and plated in poly-D-lysin coated T75 flasks (1 flask per animal). After 2-3 days in culture, OPCs growing on top of a confluent monolayer of astrocytes were detached by $6 \mathrm{~h}$ horizontal shaking. Contaminating microglial cells were eliminated by $1 \mathrm{~h}$ pre-shake and by further plating detached cells on plastic culture dishes for $1 \mathrm{~h}$. OPCs, which do not attach to plastic, were collected by gently washing the dishes and replated onto $50 \mu \mathrm{g} / \mathrm{ml}$ poly-DL-ornithine-coated (Sigma, Milan, Italy) 48 multiwell chambers. OPC cultures were maintained in Neurobasal medium (Invitrogen, Milan, Italy) containing 2\% B27, $4 \mathrm{mM}$ L-glutamine, $1 \mathrm{mM}$ Na-pyruvate, $100 \mathrm{U} / \mathrm{ml}$ penicillin, $100 \mathrm{U} / \mathrm{ml}$ streptomycin, $10 \mathrm{ng} / \mathrm{ml}$ platelet derived growth factor (PDGF-BB) and $10 \mathrm{ng} / \mathrm{ml}$ basic fibroblast growth factor (bFGF) (PeproTech EC Ltd., London, UK) to promote cell proliferation. After 2-3 days, cells were switched to a Neurobasal medium lacking growth factors in order to allow cell differentiation, and were used after 2-3 days.

\section{Results}

\subsection{Features of $M O G_{35-55}$-induced $E A E$ in NOD mice}

Autoimmunity-prone NOD mice have been used in order to reproduce a chronic encephalomyelitis [see (Dang et al., 2015) for comprehensive review]. Still, most of the studies followed disease evolution for a short period of time, and there is lack of information on the neuroand immunopathological features during the delayed phases of EAE (Basso et al., 2008; Farez et al., 2009; Huntington et al., 2006; Ichikawa et al., 2000; Mayo et al., 2016). Also, although neuropathology of immune infiltrates has been reported (Jayaraman et al., 2017), the timing of CNS immune invasion by the different immune cell types in NOD mice with EAE waits to be described in detail. We therefore first 
evaluated whether immunization with $\mathrm{MOG}_{35-55}$ at different ages causes a different disease onset. We found that onset was more rapid when immunization occurred in 10 week old mice (peak onset around day 20 post immunization), than in 6 or 8 week old mice showing onset around day $58 \pm 8$ and $50 \pm 7$ (mean \pm SEM) post immunization, respectively ( $n=25$ per group, not shown). On this basis, for the rest of the study we adopted immunization in 10 week old mice. Reportedly, disease in EAE NOD mice shows a relatively variable evolution, mostly consisting in a relapsing progressive pattern, sometimes also presenting an initial, short-lasting acute phase of neurological impairment followed by prompt remission and subsequent progression (Dang et al., 2015). Interestingly, 10 week old NOD mice immunized with MOG $_{35-55}$ displayed a gradual worsening of neurological disability without evidence of an initial acute phase (representative single mouse disease evolution patterns are shown in Fig. 1A and Fig. S1). Among 288 NOD mice immunized in our laboratory, not a single animal recovered or showed a permanent state of chronic disease. Further, as reported (Sadelain et al., 1990), NOD mice did not develop diabetes once exposed to the immunization protocol. Indeed, we did not find altered glycaemia in immunized NOD mice throughout disease evolution (Fig. S2A).

As for relapses superimposed on progressive neurological worsening, we never found episodes of acute worsening followed by remission. Rather, we noticed that in only 5 out of $90(5,6 \%)$ animals a single episode of acute, partial remission (at least of 1 point of score amelioration) superimposed on the progressive pattern of disease evolution occurred (a representative mouse is shown in Fig. 1B). When the two types of progression where cumulated in a single group, a pattern of primary progressive EAE (PPEAE) was obtained (Fig. 1C). Also, we found that incidence was $100 \%$ and all the animals reached score 4 . To better appreciate the final stages of progression in these animals, we followed disease evolution until each animal reached score 4. Unexpectedly, we found that progression rate was very variable among mice, and time at which animals reached score 4 ranged from 12 to 122 days after disease onset. Every other day evaluation of mouse weight revealed that disease onset was not preceded by weight loss and that the latter occurred from score 2 (Fig. S2B).

\subsection{Temporal kinetics of the neuroimmune response in PPEAE NOD mice}

To gather information on the qualitative and quantitative aspects of neuroimmune infiltrates in PPEAE NOD mice at different stages of neurological impairment, we next evaluated CD8 + and CD4 + T cells, CD45R + B cells and NK1.1 + NK cells in their spinal cord and spleen. As shown in Fig. 2A and B, a progressive, time-dependent increase of $\mathrm{CD} 8+$ lymphocytes occurred from score 1 , reaching a $\sim 13$-fold increase at score 2 that then plateaued up to score 4. Similarly, CD4 + T cells already infiltrated the spinal cord at score 1 and increased up to score 4 reaching a $\sim 20$-fold increment. Interestingly, we found a tendency to increase in CD45R + B cells that did not reach statistical significance at the disease stages analyzed. Similarly, NK cell number did not show any increase in the spinal cord of NOD mice during EAE progression (Fig. 2B). When the same cell populations were analyzed in the spleen, in keeping with the CNS- and epitope-restricted autoimmune response (see below), any quantitative change was detected (Fig. 2C). We next investigated whether a MOG-specific antibody response occurred during disease progression, and found that serum autoantibodies were detectable in mice at day 30 after immunization. The titer increased along with disease progression although a slight decrease was present in sera of score 4 mice (Fig. 2D).

\subsection{Evaluation of epitope spreading in PPEAE NOD mice model}

To further characterize the immunological events occurring in PPEAE NOD mice, we next evaluated possible development of an immune response to epitopes distinct from the disease-causing epitope (so-called "epitope spreading"), during disease evolution. It is well known that epitope spreading is a key determinant of the different waves of autoimmune attacks that underlie relapses at the preclinical and clinical level (McMahon et al., 2005; Quintana et al., 2014). Accordingly, we recently reported the occurrence of epitope spreading concomitant with time of relapses in SJL mice (Cavone et al., 2014). We found that lymphocytes isolated from draining lymph nodes, spleen or spinal cord of score 4 NOD mice underwent efficient proliferation if exposed to $\mathrm{MOG}_{35-55}$ but not to an additional, highly immunogenic peptides such as $\mathrm{MOG}_{8-22}$ (Fig. 3A). In keeping with this, IFN $\gamma$ was detected only in the medium of $\mathrm{MOG}_{35-55}$-exposed lymphocytes (Fig. 3B). We next investigated whether the number of $\mathrm{MOG}_{35-55}$-specific lymphocytes varies in the spinal cord of PPEAE NOD mice during disease progression. Notably, we found that MOG-specific lymphocyte proliferation from spinal cord extracts linearly increased during disease progression (Fig. 3C), as well as the extent of IFN $\gamma$ produced in the mixed lymphocytes reaction (Fig. 3D).

\subsection{Neuropathology in PPEAE NOD mice}

The progressive worsening of disability in $\mathrm{MOG}_{35-55}$-immunized NOD mice showing the classic caudo-cranial evolution of encephalomyelitis prompted us to investigate their neuropathological correlates. As shown in Fig. 4A, we found that demyelination was undetectable at score 1 , whereas appeared as vacuolized submeningeal regions of the anterior columns at score 2 , progressively broadening to
A

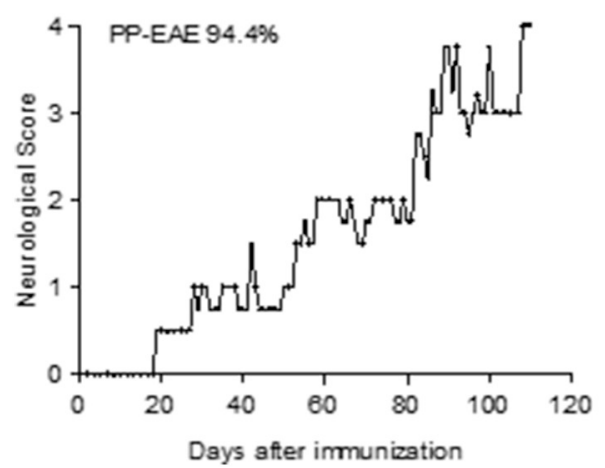

B

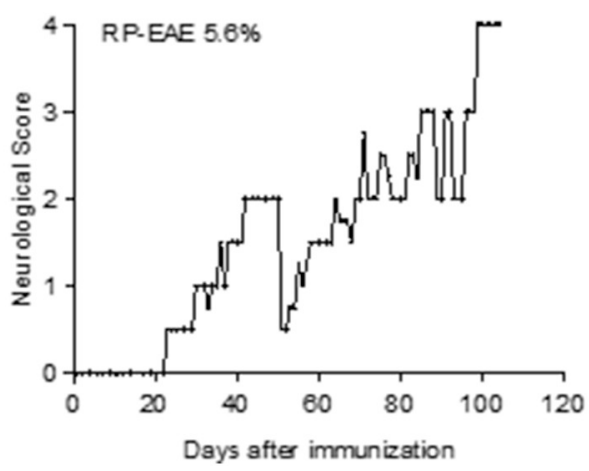

C

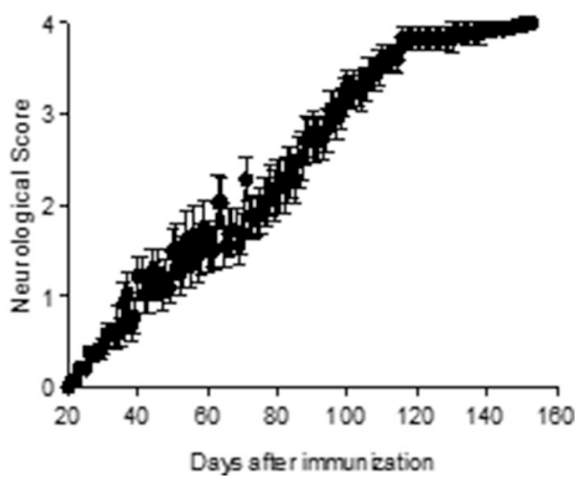

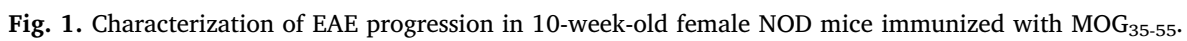

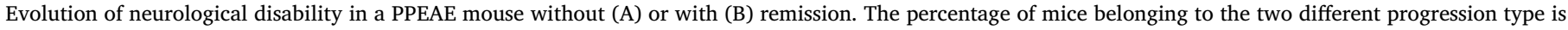
shown. (C) Cumulative evolution of neurological disability in out of 152 immunized control mice. 
A
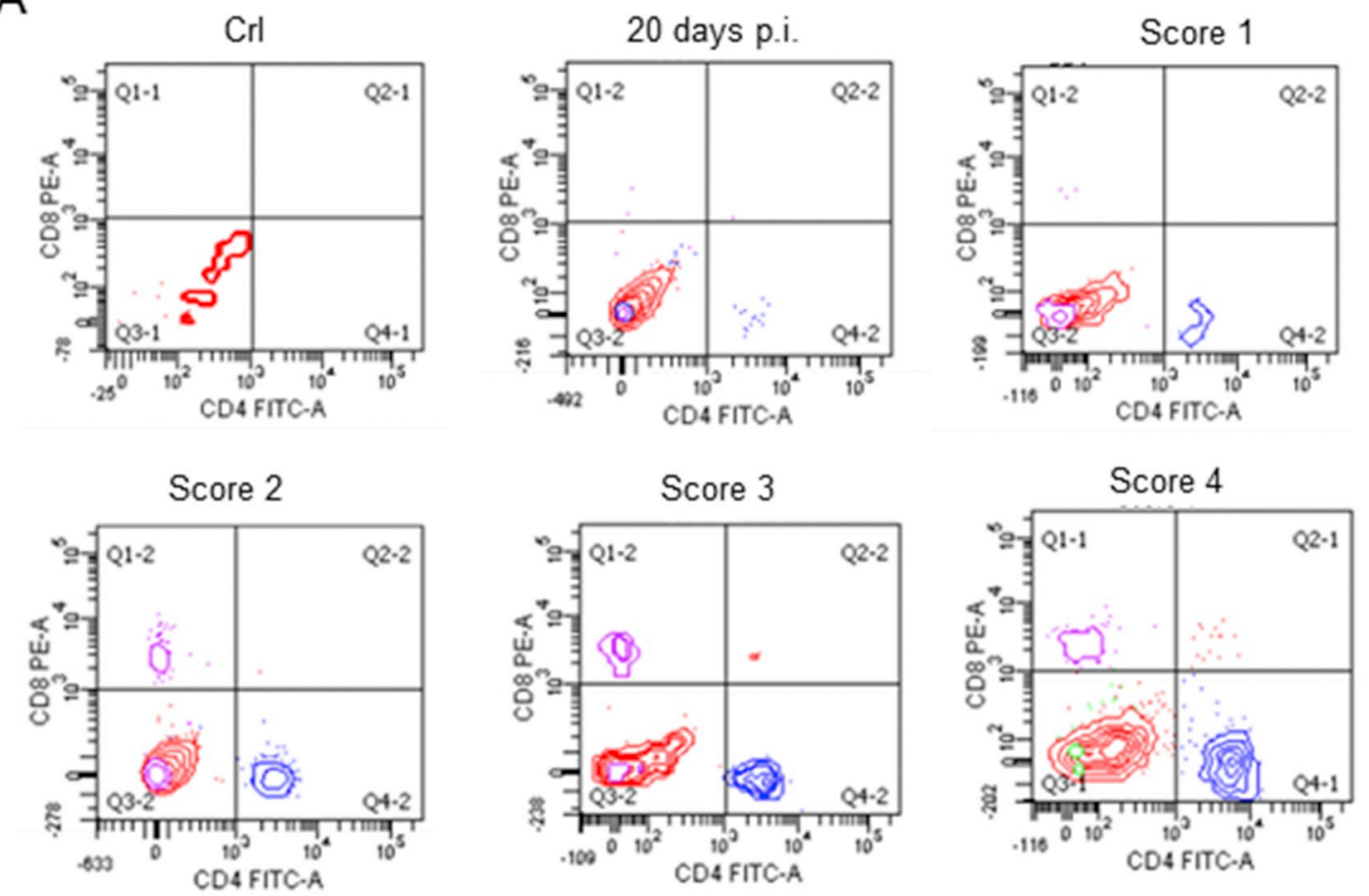

B
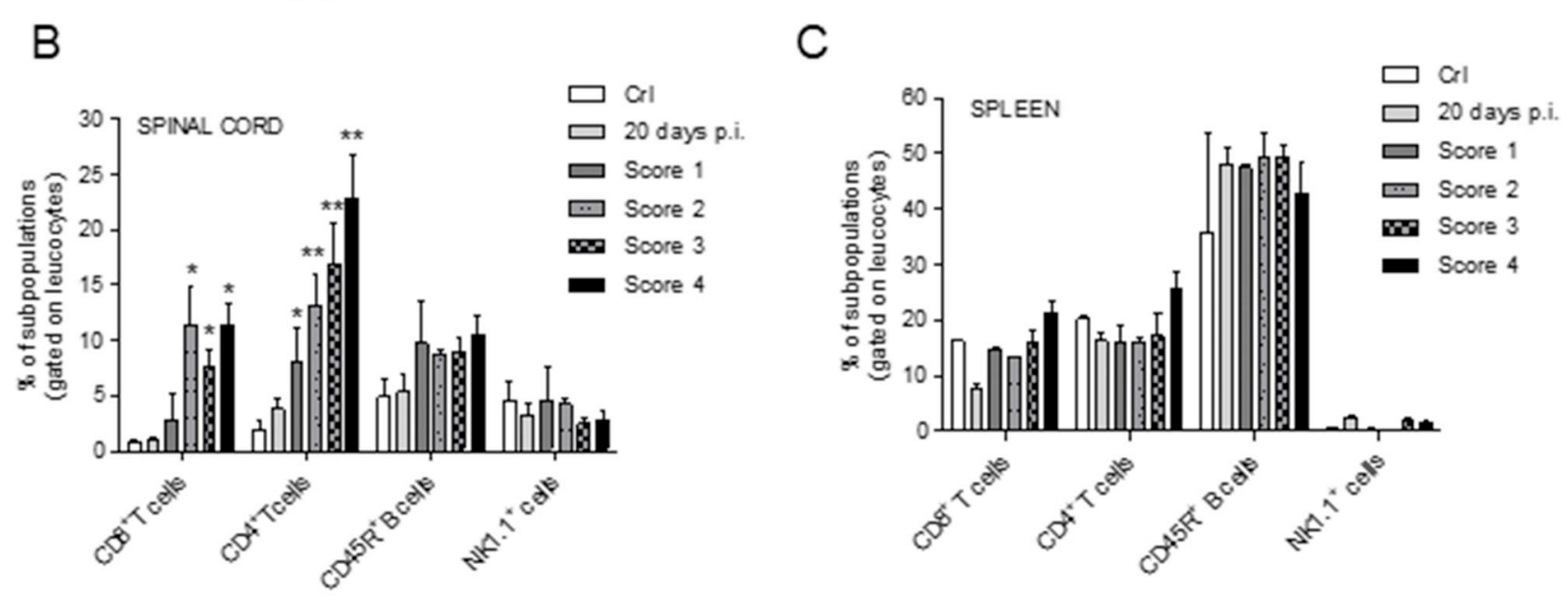

D

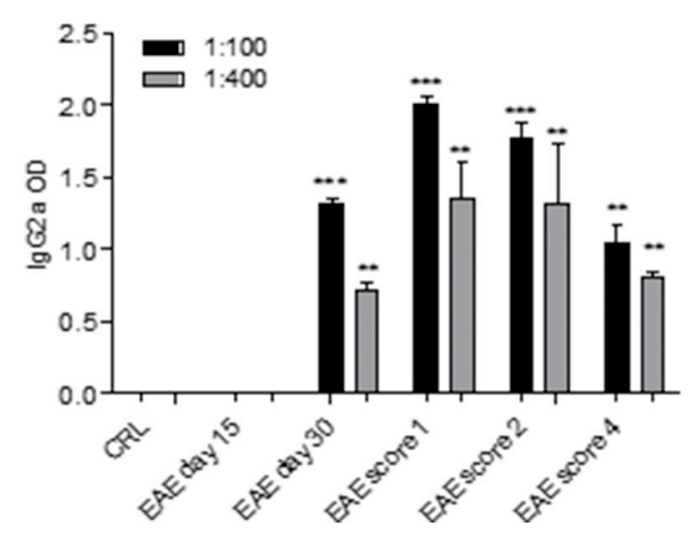

(caption on next page) 
Fig. 2. Characterization of inflammatory infiltrates and plasma Ab in PPEAE NOD mice.

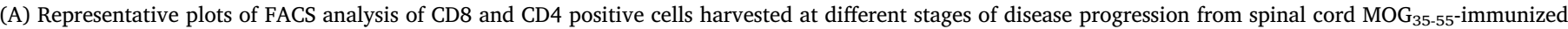

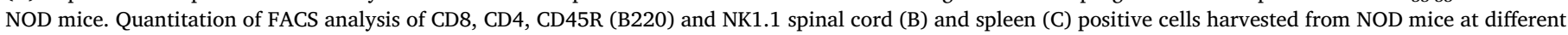

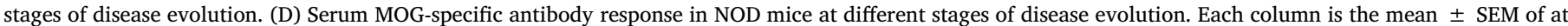

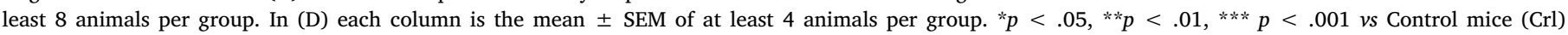
(Student's $t$-test).

the lateral and posterior columns at score 3 and 4 (Fig. 4A). Importantly, in keeping with the progressive (i.e. irreversible) neurological impairment of mice, we also found spinal cord neurodegeneration (Fig. 4A) showing similar temporal kinetics (Fig. 4B) and spatial distribution (Fig. S3) of demyelination. Importantly, we have been unable to find demyelinated regions with spared axons, suggesting that neurodegeneration rapidly occurred upon loss of myelin.

\subsection{Mitochondrial parameters in spinal cord of PPEAE NOD mice}

Since myelin loss as well as axonal degeneration were both histologically detectable only from score 2 , we then attempted to investigate whether molecular parameters of neuronal homeostasis were altered at earlier disease stages. According to a well acknowledged hypothesis, mitochondrial derangement may play a key, causative role in the pathogenesis of MS progression (Campbell et al., 2011; Dutta et al., 2006). On this basis, given that mtDNA copy number is a key molecular parameter of mitochondrial health (Blokhin et al., 2008), we first analyzed mtDNA content within the mouse lumbar spinal cord of mice with different degrees of neurological disability. Remarkably, we found that mtDNA content was already significantly reduced in mice at score 1 and further decreased in animals with a neurological score of 2 and 4 (Fig. 4C). Remarkably, the sole challenge with Freund's adjuvant plus pertussis toxin did not suffice to alter mtDNA content (Fig. S4). Given that the mtDNA parameter is inevitably confounded by the glial contribution, we next visualized mitochondria within axons of spinal cord anterior columns of score 2 mice and found that mitochondria of PPEAE mice had a pale appearance compared to those of healthy controls (Fig. 4D). Mitochondrial electron transport impairment typically prompts transition from the condensed to the orthodox conformation, a

\section{A}
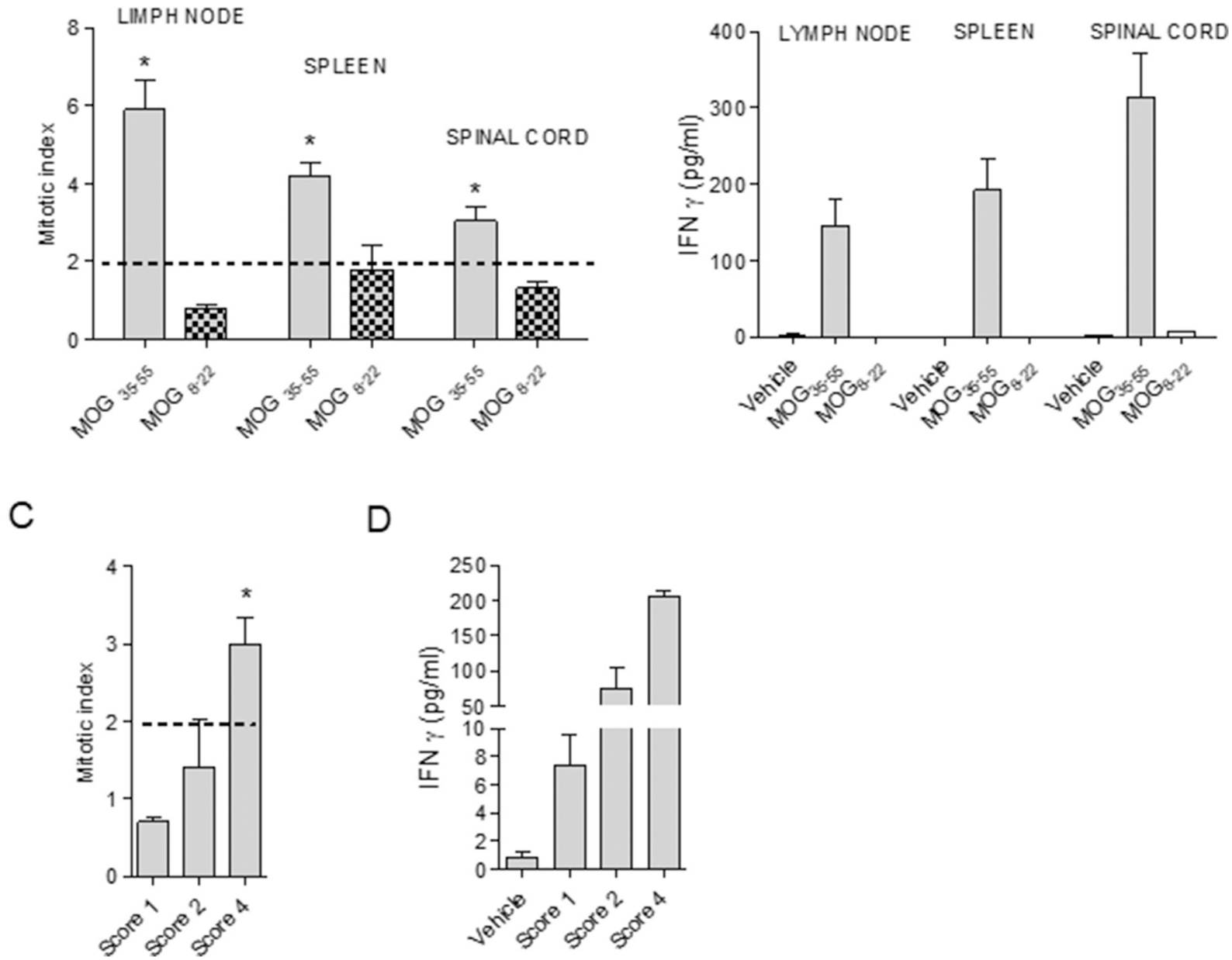

Fig. 3. Evaluation of epitope spreading in PPEAE NOD mice model.

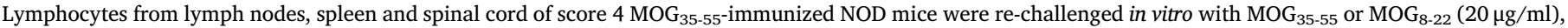

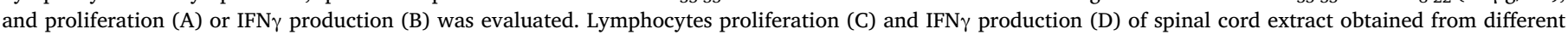

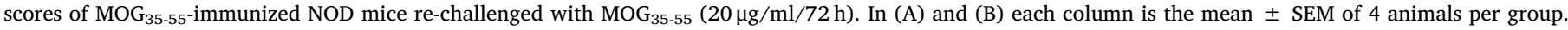

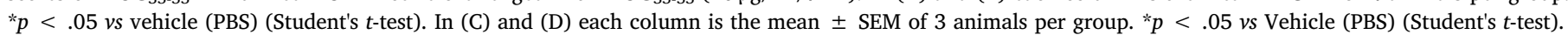


A

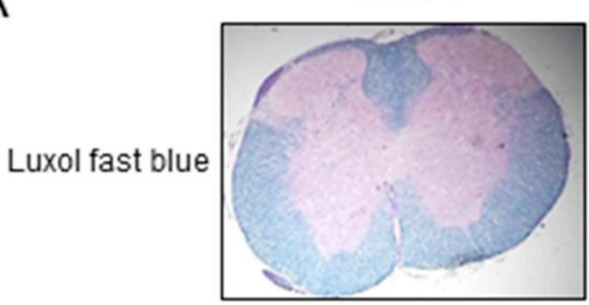

Score 1

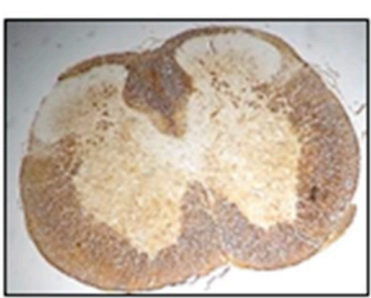

Score 2
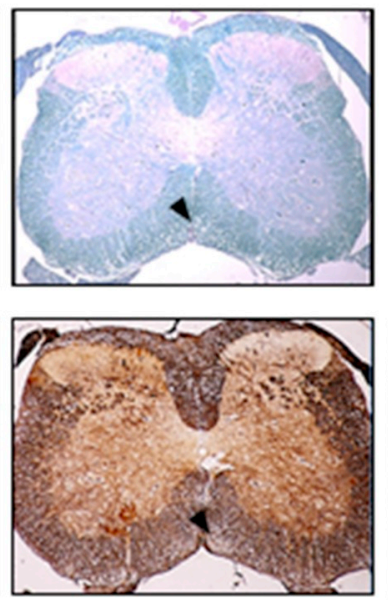

Score 3
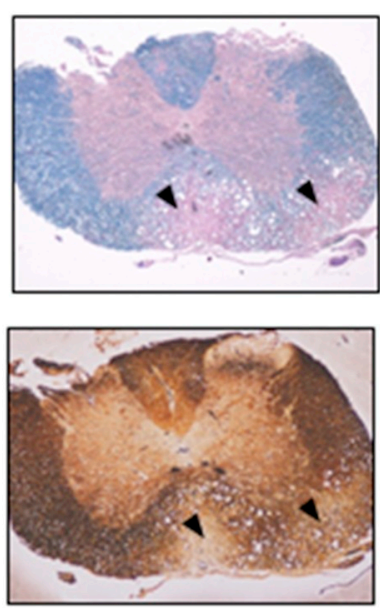

Score 4
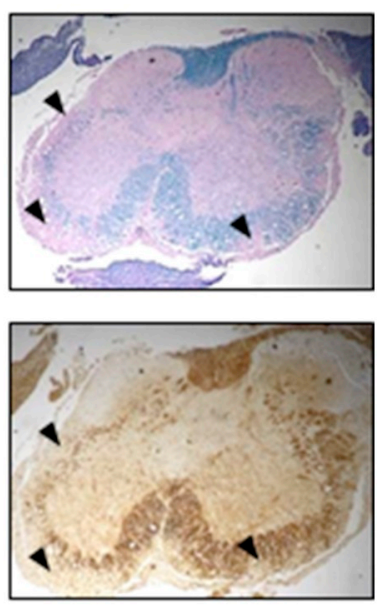

$\mathrm{B}$

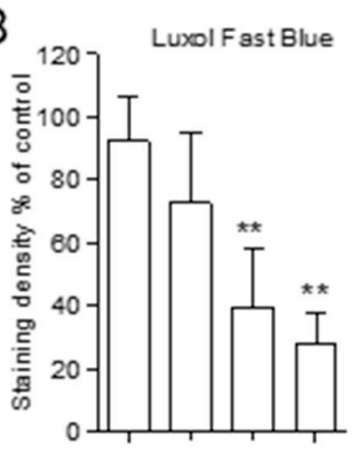

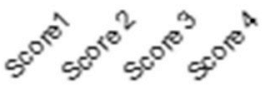

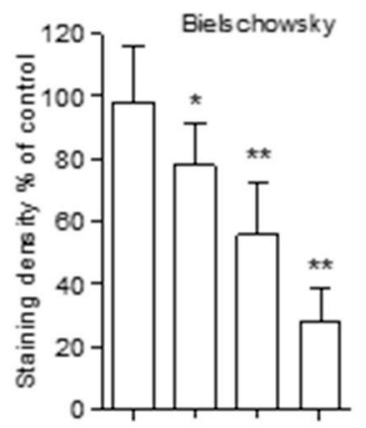

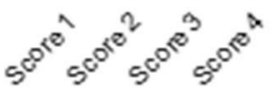

C

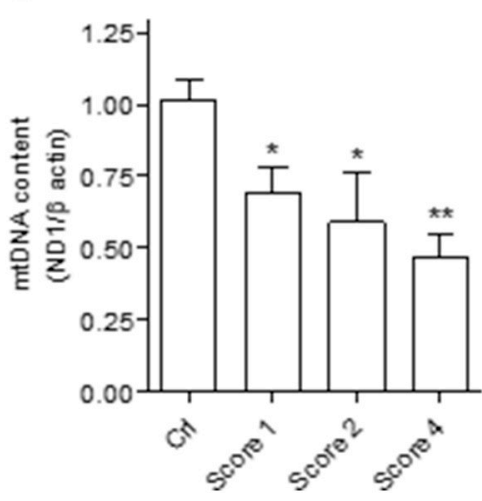

E
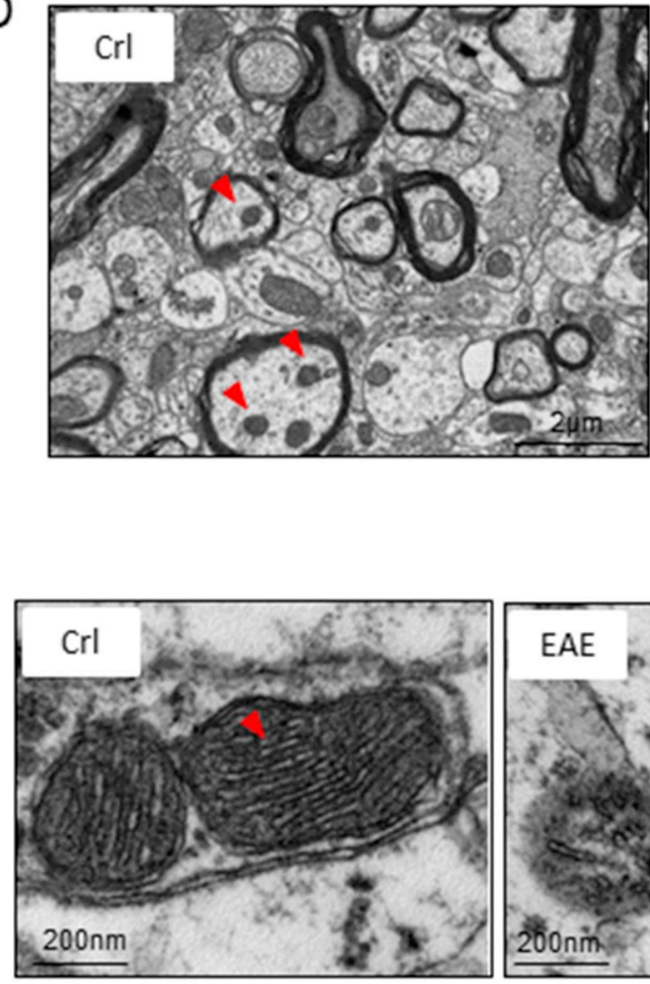

G

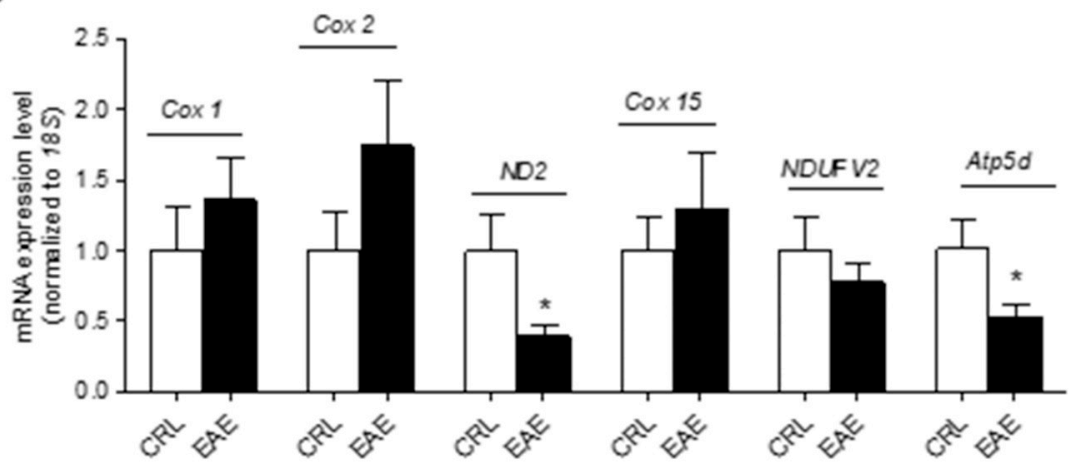


Fig. 4. Neurodegeneration in spinal cord of PPEAE NOD mice.

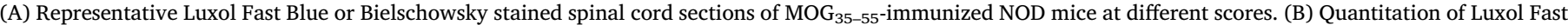

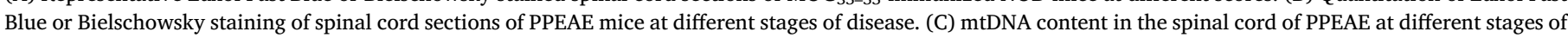

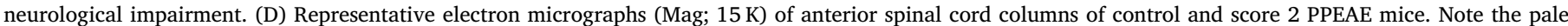

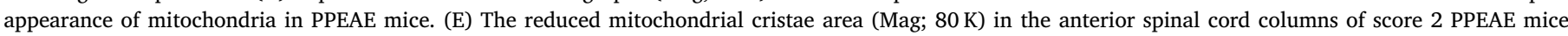

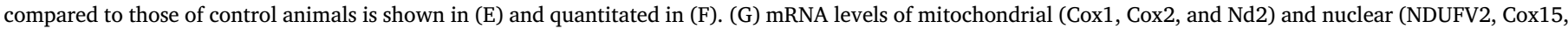

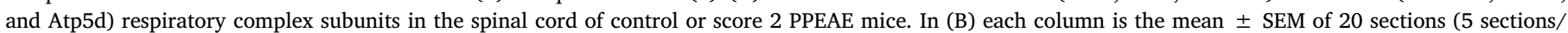

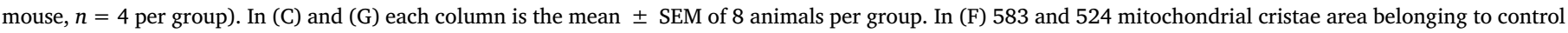

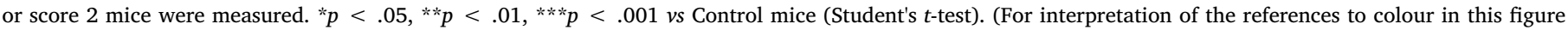
legend, the reader is referred to the web version of this article.)

morphological condition characterized by large and diffuse matrix with reduced intracristal volume (Perkins and Ellisman, 2011). In keeping with this, we found that axonal mitochondria had smaller cristae and a matrix enlarged with a watery appearance (Fig. 4E). We therefore measured the area of 583 and 524 mitochondrial cristae belonging to control or score 2 mice, respectively. As shown in Fig. 4F, mitochondrial cristae area was significantly reduced in score 2 compared to control mice. With the aim at identifying the molecular mechanisms responsible for changes in mitochondrial morphology, in light of the key role of electron transport flux in determining the condensed-toorthodox transition, we focused on respiratory complex subunit expression. The very high number of mitochondrial respiratory complex subunits limits the possibility of a detailed transcriptional analysis of all of them. Thus, we next investigated transcript levels of a limited number of mitochondrial (Cox1, Cox2, Nd2) and nuclear (Cox15, NDUFV2 and Atp5d) DNA-encoded respiratory subunits in the spinal cord of control or PPEAE mice. Interestingly, we found reduced levels of $\mathrm{Nd} 2$ and Atp5d transcript in score 2 mice compared to controls (Fig. 4G).

\subsection{Effects of dexamethasone on disease progression in PPEAE NOD mice}

Taken together, the above mentioned findings corroborated the primary progressive nature of EAE in NOD mice. Clinically, it is well known that the progressive phase of MS, both primary and secondary, is characterized by pathogenetic mechanisms in part insensitive to approved, disease-modifying immunosuppressive drugs (Baldassari and Fox, 2018). Corticosteroids are among the most notable examples of drugs that typically loose efficacy when MS turns into the progressive phase. In this light, we evaluated different treatment schedules with dexamethasone, one of the most potent corticosteroids typically able to counteract disease severity in different EAE mouse and rat models (Donia et al., 2010; Wüst et al., 2008). Acute relapses of MS patients are treated with high doses of corticosteroids for a limited, typically in the order of 5 days, period of time (Milligan et al., 1987). In keeping with this, we adopted the same treatment protocol in EAE NOD mice. As shown in Fig. 5A, high dose dexamethasone treatment $(10 \mathrm{mg} / \mathrm{kg})$ (Wüst et al., 2008) for 5 days did not alter disease progression at early (score 2 mice) or delayed (score 3 mice) phases of disease progression. To corroborate evidence that dexamethasone was unable to ameliorate neurological impairment, we also adopted a chronic treatment schedule consisting in daily, oral doses of $0.3 \mathrm{mg} / \mathrm{kg}$ from score 1 , a dose regimen that reportedly is able to ameliorate neurological impairment in numerous EAE models (Donia et al., 2010). At variance with Donia and colleagues that administered dexamethasone under prophylactic and early therapeutic regimens, we designed a clinically-relevant treatment schedule beginning at disease onset (score 1). Fig. 5B shows that even with this prolonged exposure the drug did not reduce progression rate. These findings prompted us to ask whether dexamethasone was indeed able to affect the neuroimmune response in PPEAE NOD mice. We therefore measured neuroinflammatory infiltrates, and found that $\mathrm{CD} 4+$ lymphocytes were significantly reduced in the spinal cord of mice exposed to the chronic ( 15 days) treatment protocol, with B and NK cells showing a tendency toward decrease that did not reach statistical significance (Fig. 5C). As further evidence that dexamethasone was indeed targeting autoreactive lymphocytes, we found that $\mathrm{MOG}_{35}$ ${ }_{55}$-dependent of lymphocytes proliferation was significantly reduced in spleen extracts from PPEAE mice challenged with dexamethasone for 15 days (Fig. 5D).

\subsection{Effects of bezafibrate on disease progression in PPEAE NOD mice}

The inability of dexamethasone to counteract disease progression strengthens the primary progressive nature of EAE in NOD mice. In light of the apparent pathogenetic role of mitochondrial dysfunction in MS progression, as well as the present findings showing early derangement of mitochondrial homeostasis during PPEAE NOD mice (Fig. 4C-E), we next attempted to counteract disease progression by improving mitochondrial dynamics. Several strategies designed to support mitochondrial homeostasis converge on PGC1 $\alpha$, a key protein regulating mitochondrial biogenesis and metabolism (Komen and Thorburn, 2014). We therefore studied the effects of the antidyslipidemic drug bezafibrate, a potent inducer of the PPAR-PGC1 $\alpha$ axis and promoter of mitochondrial biogenesis. We designed a treatment schedule beginning at score 1 with daily oral doses of $100 \mathrm{mg} / \mathrm{kg}$ (Wang et al., 2017) that equal the dose of 500-600 $\mathrm{mg}$ adopted in diabetic patients. As shown in Fig. 6A-C, treatment with bezafibrate did not affect disease progression, spontaneous locomotion and survival of mice with PPEAE. To understand whether bezafibrate was indeed improving mitochondrial homeostasis in PPEAE mice, we next analyzed different mitochondrial parameters in their spinal cord. We first checked for evidence that the drug was pharmacodynamically active. Among the early PPAR $\alpha$-dependent transcriptional effects of bezafibrate, it is known that it prompts a sort of amplification cycle by inducing expression of PGC1 $\alpha$ and PPAR $\alpha$ itself (Augustyniak et al., 2018). Interestingly, we found that transcripts for these two genes were reduced in the spinal cord of score 2 mice, and bezafibrate treatment restored expression levels to control values (Fig. 6D). We went on and analyzed whether mitochondrial parameters found deranged in PPEAE mice were also restored by bezafibrate. We found that drug treatment was unable to counteract reduction of mtDNA copy number (Fig. 6E) but sufficed to prevent reduction of mitochondrial cristae area (Fig. $6 \mathrm{~F}$ and G), the latter being a parameter that can be reliably ascribed to axons. When the impact of bezafibrate on expression levels of mitochondrial respiratory subunits was evaluated, we found that drug treatment restored Atp5d transcripts to control values, having no effects on those of Cox1, Cox2, Nd2, NDUFV2 and Cox15 (not shown). Collectively, these findings indicate that activation of the PPAR $\alpha$-PGC1 $\alpha$ axis occurs in mice with PPEAE even though the ensuing partial restoration of mitochondrial homeostasis by bezafibrate does not translate into neurological improvement. These findings therefore question the translational potential of bezafibrate-like drugs in the treatment of MS progression.

\subsection{Effects of biotin on disease progression in PPEAE NOD mice}

Biotin, or vitamin B7, is the co-enzyme of several carboxylases also operating in mitochondria at the tricarboxylic acid cycle (Tong, 2013). By so doing, biotin might sustain energy production within the CNS (Ochoa-Ruiz et al., 2015), and may also support ATP production in 
A

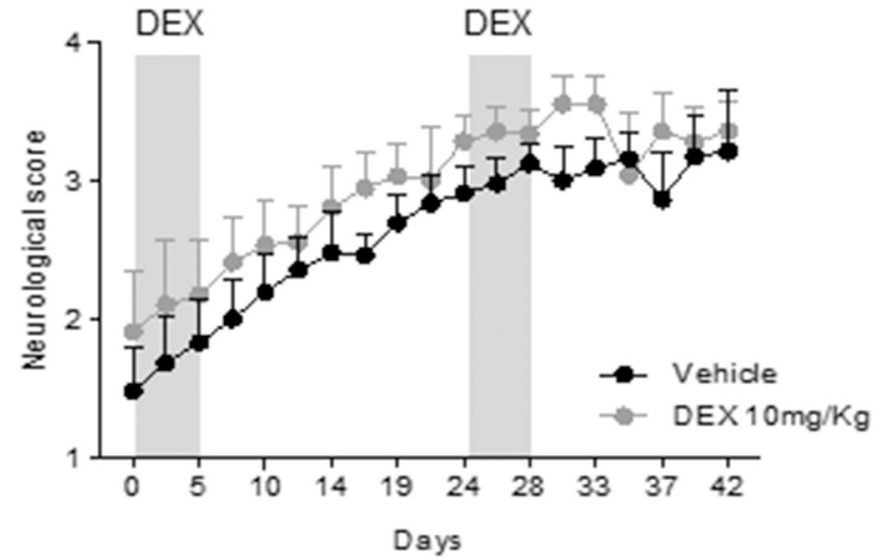

B

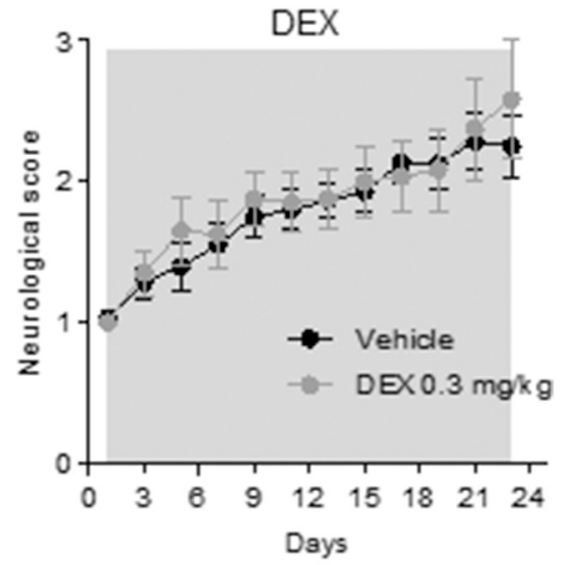

C
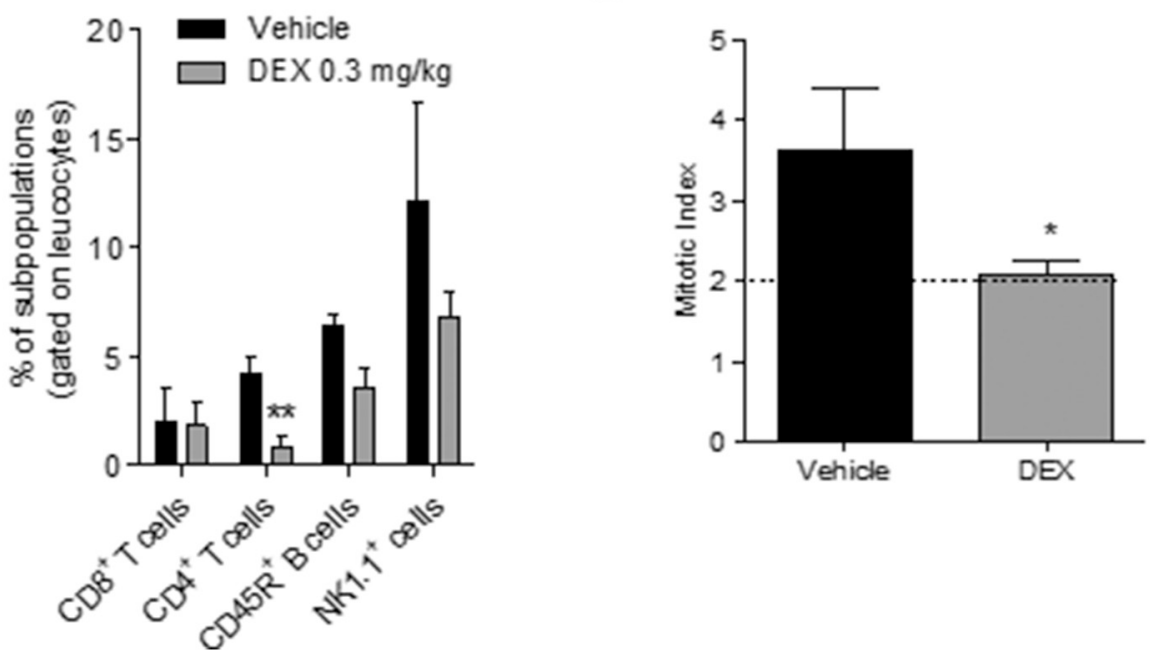

Fig. 5. Effects of dexamethasone on disease progression in PPEAE NOD mice.

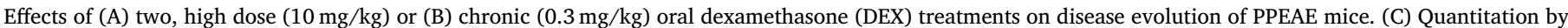

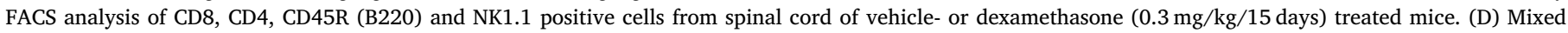

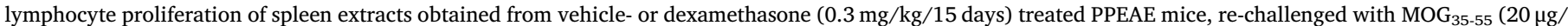
$\mathrm{ml} / 72 \mathrm{~h}$ ). Each point/column represents the mean \pm SEM of 9 (Vehicle) and 10 (DEX) animals per group. * $p<.05$, ** $p<.01 v s$ Vehicle (Student's $t$-test).

neurons exposed to virtual hypoxia (Sedel et al., 2016). Accordingly, daily oral biotin reduced progression of disability in two clinical trials that collectively enrolled $>250$ PMS patients (Birnbaum and Stulc, 2017; Tourbah et al., 2018). Still, to the best of our knowledge biotin has been tested neither in preclinical PMS models nor in in vitro settings aimed at investigating its bioenergetic or cytoprotective effects on neural cells. We therefore first checked whether biotin increases ATP in cultured mouse cortical neurons, and found that it did not affect ATP content at 10 and $100 \mu \mathrm{M}$, and, surprisingly, reduced them at $1 \mathrm{mM}$ (Fig. 7A). Similarly, the vitamin at $100 \mu \mathrm{M}$ was unable to afford protection from glutamate-dependent excitotoxicity $(100 \mu \mathrm{M} / 24 \mathrm{~h})$ (Fig. 7B), a type of cell death involved in neurodegeneration during MS (Pitt et al., 2000), and amplified by early bioenergetic failure (Matute et al., 2001). Similarly, when tested in cultures of primary rat oligodendrocytes, biotin reduced ATP at $1 \mathrm{mM}$ (Fig. 7C), and at $100 \mu \mathrm{M}$ did not counteract cytotoxicity induced by the demyelinating agent cuprizone $(50 \mu \mathrm{M} / 6 \mathrm{~h})$ (Fig. 7D). Unfortunately, these negative results were also confirmed in vivo. Indeed, with a post-treatment protocol (from score 1) and daily oral dose of $50 \mathrm{mg} / \mathrm{kg}$ bioequivalent to that adopted in PMS patients (Tourbah et al., 2018), biotin treatment did not affect disability progression (Fig. 7E), spontaneous locomotion (Fig. 7F) or survival (Fig. 7G) in PPEAE mice. Finally, we also asked whether biotin might somehow affect the extend of neuroinflammatory infiltrates, but found that PPEAE mice exposed to the vitamin had the same number of $\mathrm{T}, \mathrm{B}$ and NK cells in the spinal cord compared to animals receiving vehicle (Fig. 7H).

\section{Discussion}

The present study furthers our understanding of EAE in NOD mice and show that, akin to PMS, it is featured by progressive accumulation of disability, early mitochondrial dysfunction, substantial neurodegeneration and insensitivity to corticosteroids.

Literature about animal models of PMS is somehow confounding. For instance, analysis of EAE evolution in Biozzi mice as a PMS model reveals that animals undergo a stable rather than progressive disease (Lassmann and Bradl, 2017). Also, how EAE in NOD mice strictly recapitulates PMS features has never been carefully demonstrated. In particular, a detailed qualitative and quantitative analysis of neuroimmune infiltrates as well as their temporal relationship with disease evolution still waited to be shown. At variance with prior work showing a first remission phase in NOD mice followed by disease progression 
A

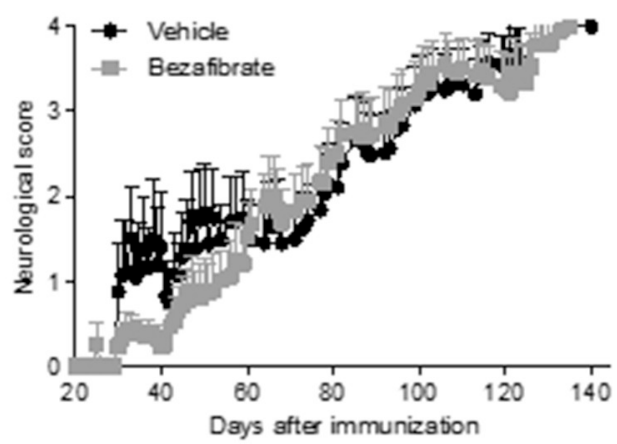

D

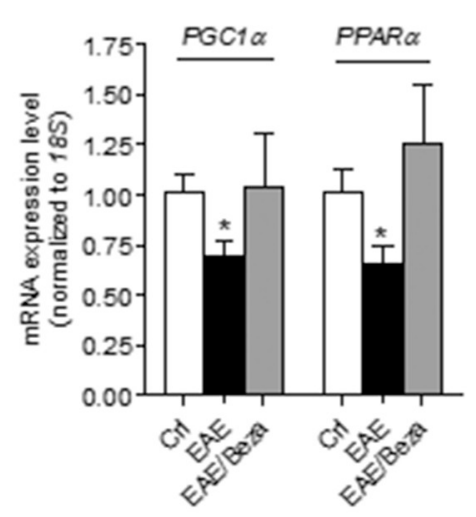

$\mathrm{F}$

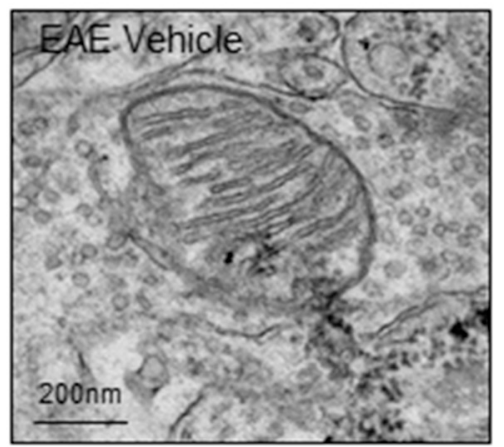

B
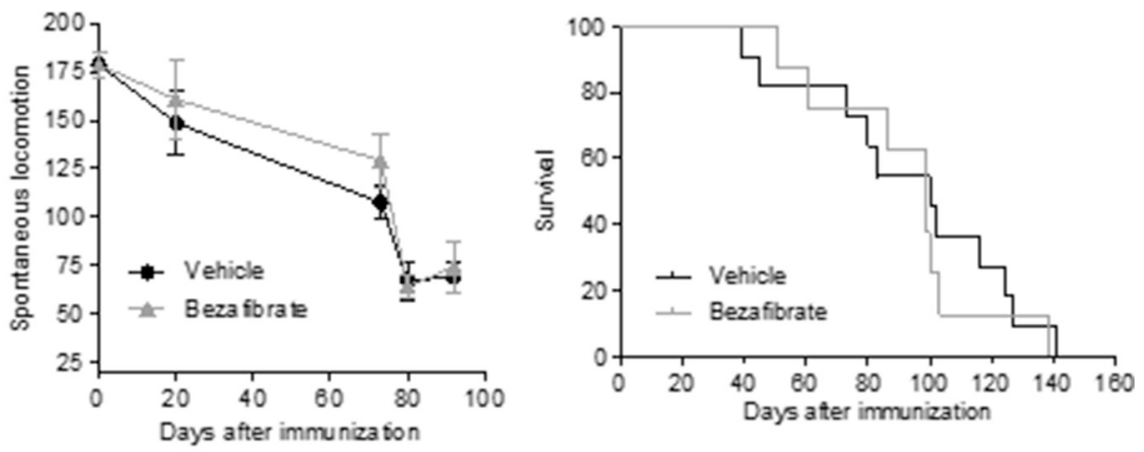

E
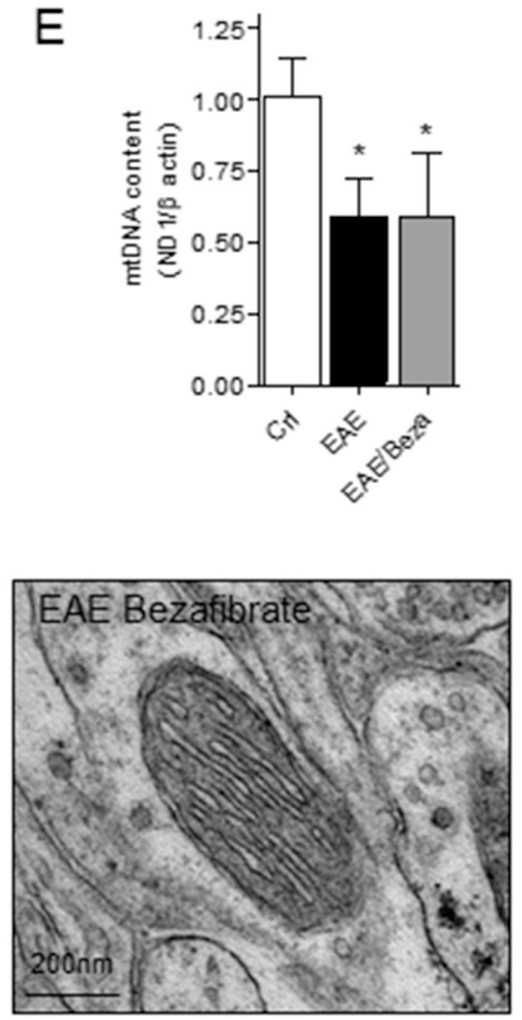

G

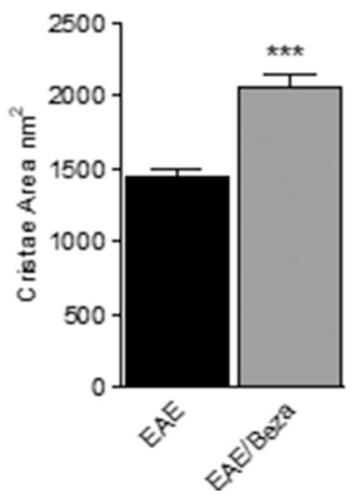

Fig. 6. Effects of bezafibrate on disease progression in PPEAE NOD mice.

Effects of daily, oral treatment with bezafibrate $(100 \mathrm{mg} / \mathrm{kg}$ from score 1) on neurological score (A), spontaneous locomotion (B) and survival (C) in PPEAE NOD mice. mRNA levels of PGC1 $\alpha$ and PPAR $\alpha$ (D) or mtDNA content (E) in the spinal cord of control or PPEAE mice (score 2) treated or not with bezafibrate (from score 1 to score 2). The effect of bezafibrate treatment on mitochondrial cristae area (Mag; $80 \mathrm{~K}$ ) in the anterior spinal cord columns of score $2 \mathrm{PPEAE}$ mice is shown in (F) and quantitated in (G). In (D-F) mice treated with bezafibrate at least for 30-35 days were used only. In (A), (B) and (C) 20 animals per group. In (D) and (E), each column is the mean \pm SEM of 6 animals per group. In (G) 524 and 564 mitochondrial cristae area belonging to score 2 PPEAE or PPEAE plus bezafibrate mice were measured. ${ }^{*} p<.05,{ }^{* * *} p<.001$ vs Crl or EAE/beza. ANOVA plus Tukey's post hoc test.

(Dang et al., 2015), we show here a primary progressive pattern of disease evolution. At present, we are unable to provide an explanation for such finding, but it is worth noting that we immunized 288 mice and none showed an early remission phase. We also report that neuroimmune invasion linearly increases with time and parallels severity of disease evolution. We believe that this is a key finding of the present study. Indeed, in RREAE models such as that of SJL mice, the autoimmune attack to the CNS massively occurs in the first phase of the disease and then follows with waves of reduced intensity that, remarkably, shortly anticipate disease relapses (Cavone et al., 2015). The kinetics of infiltrates found in NOD mice, therefore, are original and not consistent with those found in RREAE mice. Rather, we reason that the slow, progressive increase of immune infiltrates in NOD mice might represent, at least in part, an inflammatory process secondary to disease evolution. Obviously, this interpretation is at odds with evidence that PPEAE is triggered by primary sensitization to a myelin antigen. Also, the strict temporal and spatial relationship between demyelination and axonal damage we found in PPEAE NOD mice suggests primary myelin loss as causal to neurodegeneration. Still, three key findings of the present study support the hypothesis that neurodegeneration is a 
A

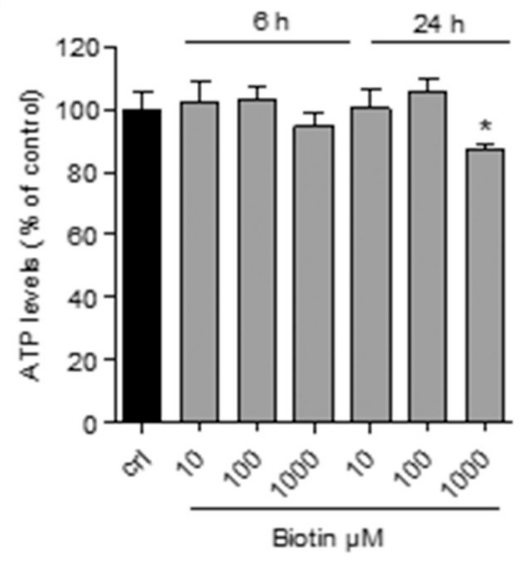

E

$D$
B
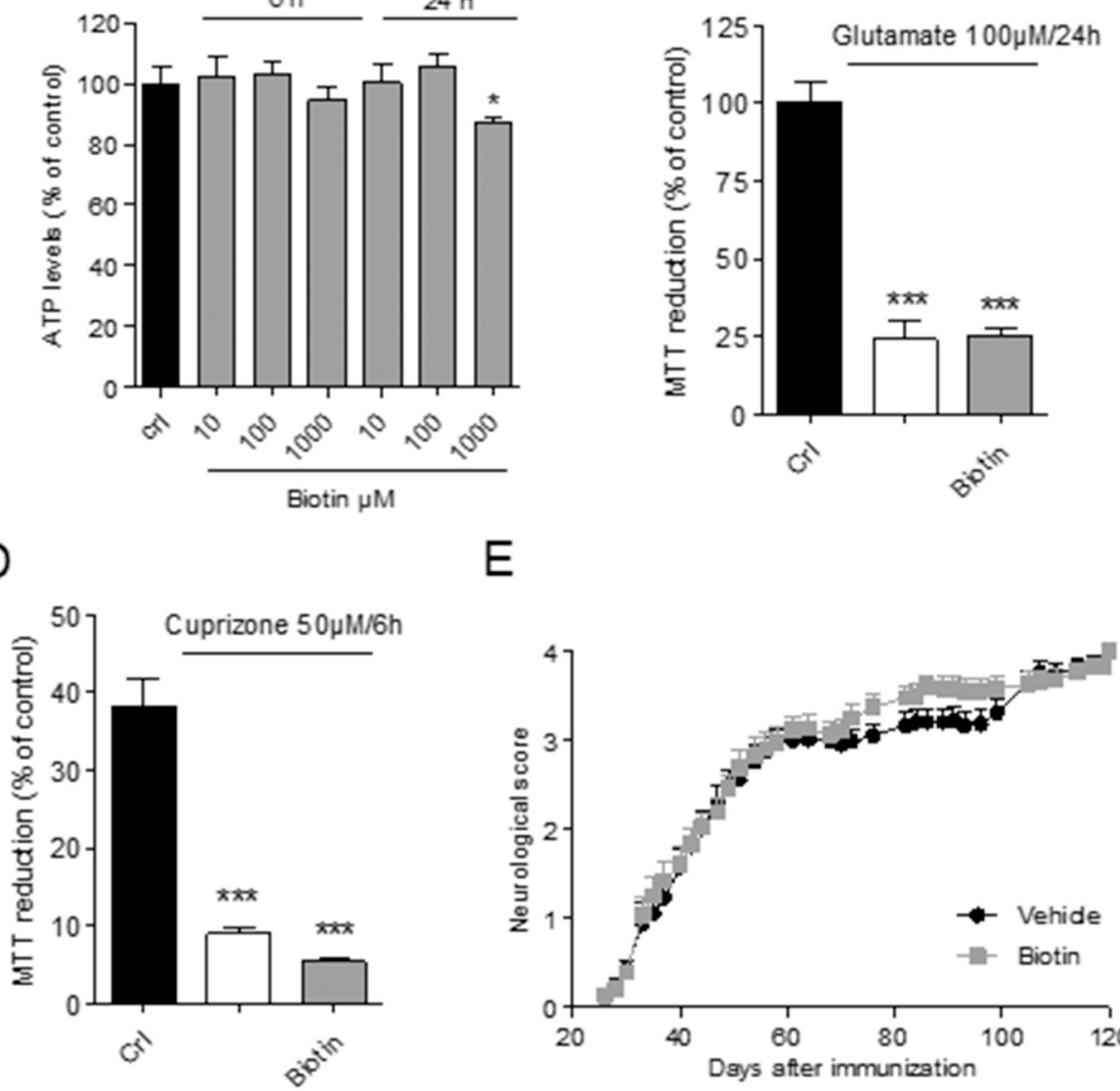

G

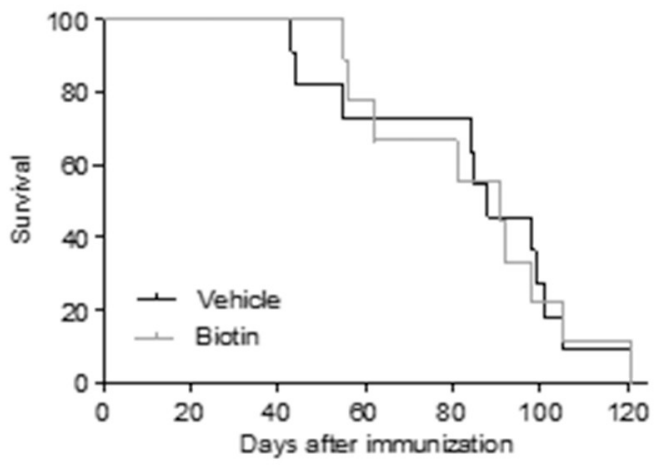

\section{$\mathrm{H}$}
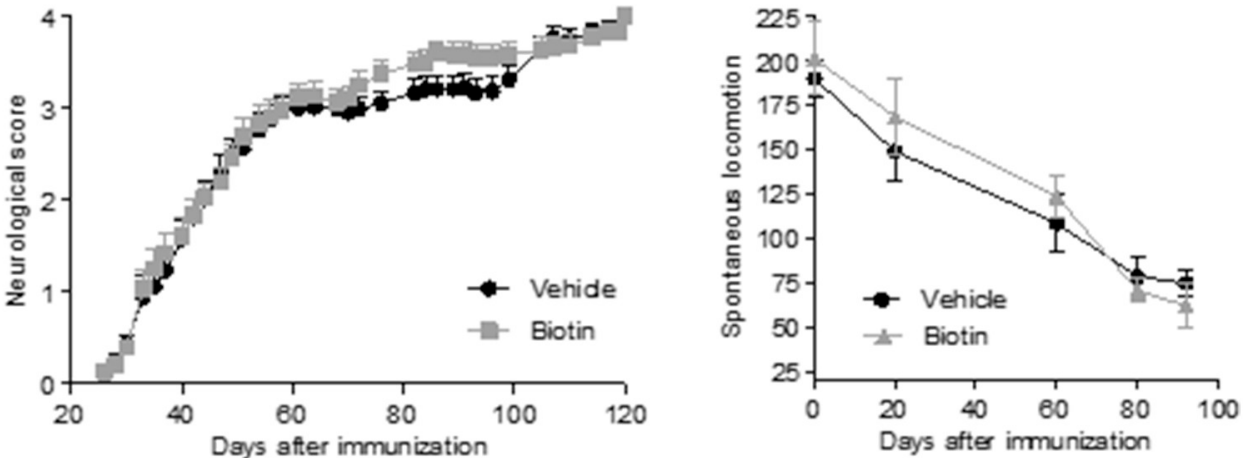

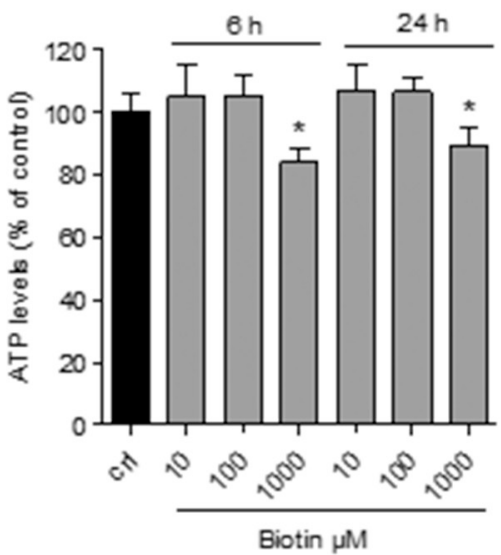

F

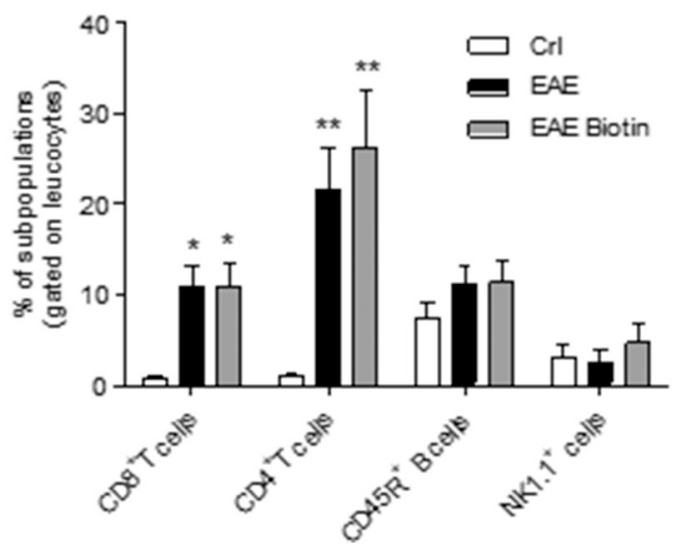

Fig. 7. Effects of biotin on disease progression in PPEAE NOD mice.

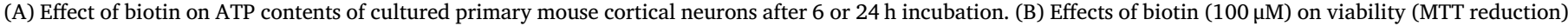

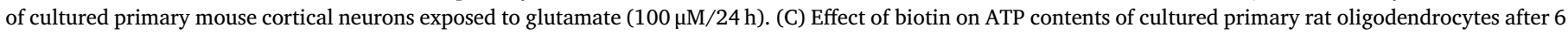

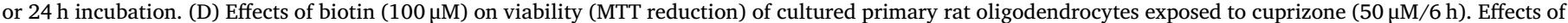

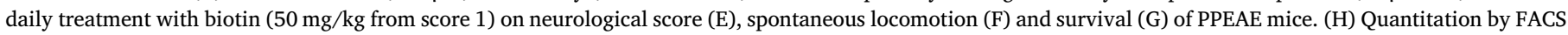

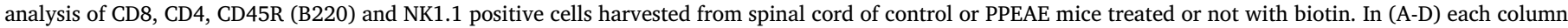

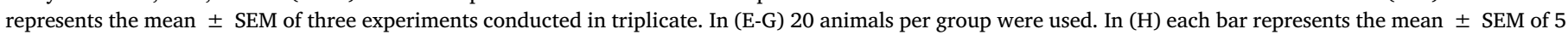
mice. ${ }^{*} p<.05,{ }^{*} p<.01,{ }^{* * *} p<.001$ vs control/vehicle. ANOVA plus Tukey's post hoc test.

process somehow independent from neuroinflammation in NOD mice. First, two different dexamethasone treatment paradigms analogues to those counteracting EAE in different mouse strains (Donia et al., 2010) did not affect disease evolution in PPEAE NOD mice in spite of evidence that the drug reduced both spinal cord immune infiltrates and lymphocyte proliferation to MOG. Second, we found that mtDNA copy number, a prototypical index of mitochondrial functioning, is already reduced at score 1 when CNS immune infiltrates are minimal and 
neurodegeneration is not detectable. This suggests that neurodegeneration originates from primary dysfunctional homeostasis within neural cells and seems not be a consequence of the prolonged neuroinflammatory response. We also show condensed to orthodox mitochondrial transition, decrease of cristae area, as well as reduced transcripts for respiratory complex subunits in the spinal cord of PPEAE NOD mice. Remarkably, these findings are in keeping with derangement of transcriptional homeostasis of respiratory complexes as well as mtDNA mutations found in the CNS of PMS patients (Campbell and Mahad, 2018). Third, lack of spreading toward MOG $_{8-22}$ in PPEAE NOD mice, suggests that compared to RREAE SJL mice (Cavone et al., 2014), accumulation of immune cells in their CNS might not be due to superimposed waves of autoreactive lymphocytes. In this light, our findings suggest that the slow accumulation of $\mathrm{T}$ cells found in immunized NOD mice is, at least in part, driven by autonomous, self-sustaining neurodegenerative events that, at a certain time point of disease evolution, take over the primary autoimmune response in terms of disease pathogenesis. This interpretation is corroborated by the notion that the sole pertussis toxin (i.e. without $\mathrm{MOG}_{35-55}$ challenge) suffices to trigger EAE in NOD mice (Winer et al., 2001), as well as with evidence of neurodegeneration in the absence of inflammation in cortical plaques of PMS patients (Peterson et al., 2001; Vercellino et al., 2005; Wegner et al., 2006). Of course, identification of the mechanisms operating the pathogenetic shift from autoimmunity to self-sustaining neurodegeneration, as well as their timing, would be instrumental to decipher the molecular basis of EAE/MS progression.

We also originally report that neither bezafibrate nor biotin was able to alter disease evolution in PPEAE NOD mice. Of note, both drugs are routinely used in the clinic and might have had a remarkable translational potential. Reportedly, bezafibrate promotes mitochondriogenesis and a transcriptional response that supports mitochondrial functioning (Noe et al., 2013). In keeping with this, the drug restored homeostasis of both PGC1 $\alpha$ and PPAR $\alpha$ transcripts as well as mitochondrial cristae morphology (a parameter directly related to bioenergetic efficiency of the organelles) in PPEAE mice, indicating that it was pharmacodynamically active. Notably, the reduced transcript levels of PGC1 $\alpha$ we found in PPEAE NOD mice is consistent with the diminished PGC1 $\alpha$ expression in the brain cortex of PMS patients (Witte et al., 2013a; Witte et al., 2013b). However, evidence that bezafibrate did not affect disease evolution indicate that the sole impact on mitochondrial dynamics do not suffice to counteract the complex events responsible for neurodegeneration and disease progression. Data, therefore, on the one hand corroborate evidence that PGC1 $\alpha$ activity is dysfunctional in PPEAE and PMS, but on the other weaken its relevance as a PMS therapeutic target.

As for biotin, the inability to counteract disease evolution is of particular relevance in light of its current testing in patients with progressive MS. In spite of contrasting findings obtained in recently-concluded trials, and its current sperimentation in a large phase III trial including patients with primary or secondary progressive MS (Birnbaum and Stulc, 2017; Tourbah et al., 2018), information on the effects of biotin in preclinical models of MS is lacking. Of note, in our study we exposed EAE NOD mice to chronic treatment with an oral dose of $50 \mathrm{mg} / \mathrm{kg}$ that corresponds to a human equivalent dose of $291 \mathrm{mg}$, consistent with that of $300 \mathrm{mg}$ adopted in PMS patients (Tourbah et al., 2018). Even though this dose appears excessive if one considers the human biotin daily need of $30 \mu \mathrm{g}$ (Riveron-Negrete and FernandezMejia, 2017), chronic treatment in NOD mice was safe and well tolerated. It is also worth noting that, at variance with the claim that biotin boosts bioenergetics by promoting Kreb's cycle efficiency, we have been unable to find any effect of the vitamin on ATP content in primary cultures of both cortical neurons and oligodendrocytes. These findings, along with our data showing that biotin does not increase resistance of neurons to excitotoxicity or of oligodendrocytes to cuprizone, are in keeping with its inability to reduce disease progression in PPEAE NOD mice, as well as with work showing worsening of PMS patients on high dose biotin (Birnbaum and Stulc, 2017). The estimated completion date of the current multicenter clinical trial with biotin in PMS is September 2019 (http://clinicaltrials.gov, NCT02936037). At that time it will be possible to learn whether our negative results on biotin were predictive of clinical failure. This information will also corroborate the relevance of the PPEAE NOD mouse model as a reliable tool to identify efficacious treatments for MS progression.

Supplementary data to this article can be found online at https:// doi.org/10.1016/j.expneurol.2019.113065.

\section{Declaration of Competing Interest}

None.

\section{Acknowledgments}

This work was supported by grants from Italian Foundation for Multiple Sclerosis 2014/R/6 (recipient AC), Regione Toscana Rare Disease Projects-Heath Projects 2007 and 2009 (recipient AC), AIRC and Fondazione CR Firenze under IG 2017 - ID. 20451 project (P.I. Alberto Chiarugi).

\section{References}

Augustyniak, J., Lenart, J., Gaj, P., Kolanowska, M., Jazdzewski, K., Stepien, P.P., Buzanska, L., 2018. Bezafibrate upregulates mitochondrial biogenesis and influence neural differentiation of human-induced pluripotent stem cells. Mol. Neurobiol. 56, $4346-4363$.

Baldassari, L.E., Fox, R.J., 2018Baldassari and F. Therapeutic advances and challenges in the treatment of progressive multiple sclerosis. Drugs. 78, 1549-1566.

Basso, A.S., Frenkel, D., Quintana, F.J., Costa-Pinto, F.A., Petrovic-Stojkovic, S., Puckett, L., Monsonego, A., Bar-Shir, A., Engel, Y., Gozin, M., Weiner, H.L., 2008. Reversal of axonal loss and disability in a mouse model of progressive multiple sclerosis. J. Clin. Invest. 118, 1532-1543.

Birnbaum, G., Stulc, J., 2017. High dose biotin as treatment for progressive multiple sclerosis. Mult. Scler. Relat. Disord. 18, 141-143.

Bjartmar, C., Kidd, G., Mork, S., Rudick, R., Trapp, B.D., 2000. Neurological disability correlates with spinal cord axonal loss and reduced $\mathrm{N}$-acetyl aspartate in chronic multiple sclerosis patients. Ann. Neurol. 48, 893-901.

Bjartmar, C., Wujek, J.R., Trapp, B.D., 2003. Axonal loss in the pathology of MS: consequences for understanding the progressive phase of the disease. J. Neurol. Sci. 206 $165-171$.

Blokhin, A., Vyshkina, T., Komoly, S., Kalman, B., 2008. Variations in mitochondrial DNA copy numbers in MS brains. J. Mol. Neurosci. 35, 283-287.

Buonvicino, D., Mazzola, F., Zamporlini, F., Resta, F., Ranieri, G., Camaioni, E., Muzzi, M., Zecchi, R., Pieraccini, G., Dolle, C., Calamante, M., Bartolucci, G., Ziegler, M., Stecca, B., Raffaelli, N., Chiarugi, A., 2018. Identification of the nicotinamide salvage pathway as a new toxification route for antimetabolites. Cell. Chem. Biol. 25, $471-482$.

Campbell, G., Mahad, D., 2018. Neurodegeneration in progressive multiple sclerosis. Cold Spring Harb. Perspect. Med. 8.

Campbell, G.R., Ziabreva, I., Reeve, A.K., Krishnan, K.J., Reynolds, R., Howell, O. Lassmann, H., Turnbull, D.M., Mahad, D.J., 2011. Mitochondrial DNA deletions and neurodegeneration in multiple sclerosis. Ann. Neurol. 69, 481-492.

Cavone, L., Aldinucci, A., Ballerini, C., Biagioli, T., Moroni, F., Chiarugi, A., 2011. PARP-1 inhibition prevents CNS migration of dendritic cells during EAE, suppressing the encephalitogenic response and relapse severity. Mult. Scler. 17, 794-807.

Cavone, L., Peruzzi, B., Caporale, R., Chiarugi, A., 2014. Long-term suppression of EAE relapses by pharmacological impairment of epitope spreading. Br. J. Pharmacol. 171, 1501-1509.

Cavone, L., Felici, R., Lapucci, A., Buonvicino, D., Pratesi, S., Muzzi, M., Hakiki, B., Maggi, L., Peruzzi, B., Caporale, R., Annunziato, F., Amato, M.P., Chiarugi, A., 2015. Dysregulation of sphingosine 1 phosphate receptor-1 (S1P1) signaling and regulatory lymphocyte-dependent immunosuppression in a model of post-fingolimod MS rebound. Brain Behav. Immun. 50, 78-86.

Chiarugi, A., Moskowitz, M.A., 2003. Poly(ADP-ribose) polymerase-1 activity promotes NF-kappaB-driven transcription and microglial activation: implication for neurodegenerative disorders. J. Neurochem. 85, 306-317.

Ciotti, J.R., Cross, A.H., 2018. Disease-modifying treatment in progressive multiple sclerosis. Curr. Treat. Options Neurol. 20, 12.

Dang, P.T., Bui, Q., D'Souza, C.S., Orian, J.M., 2015. Modelling MS: Chronic-Relapsing EAE in the NOD/Lt mouse strain. Curr. Top. Behav. Neurosci. 26, 143-177.

Donia, M., Mangano, K., Quattrocchi, C., Fagone, P., Signorelli, S., Magro, G., Sfacteria, A., Bendtzen, K., Nicoletti, F., 2010. Specific and strain-independent effects of dexamethasone in the prevention and treatment of experimental autoimmune encephalomyelitis in rodents. Scand. J. Immunol. 72, 396-407.

Dutta, R., McDonough, J., Yin, X., Peterson, J., Chang, A., Torres, T., Gudz, T., Macklin, W.B., Lewis, D.A., Fox, R.J., Rudick, R., Mirnics, K., Trapp, B.D., 2006. Mitochondrial 
dysfunction as a cause of axonal degeneration in multiple sclerosis patients. Ann.Neurol. 59, 478-489.

Farez, M.F., Quintana, F.J., Gandhi, R., Izquierdo, G., Lucas, M., Weiner, H.L., 2009. Tolllike receptor 2 and poly(ADP-ribose) polymerase 1 promote central nervous system neuroinflammation in progressive EAE. Nat.Immunol. 10, 958-964.

Felici, R., Buonvicino, D., Muzzi, M., Cavone, L., Guasti, D., Lapucci, A., Pratesi, S., De Cesaris, F., Luceri, F., Chiarugi, A., 2017. Post onset, oral rapamycin treatment delays development of mitochondrial encephalopathy only at supramaximal doses. Neuropharmacology. 117, 74-84.

Fumagalli, M., Daniele, S., Lecca, D., Lee, P.R., Parravicini, C., Fields, R.D., Rosa, P., Antonucci, F., Verderio, C., Trincavelli, M.L., Bramanti, P., Martini, C., Abbracchio, M.P., 2011. Phenotypic changes, signaling pathway, and functional correlates of GPR17-expressing neural precursor cells during oligodendrocyte differentiation. J. Biol. Chem. 286, 10593-10604.

Galeotti, N., Bartolini, A., Ghelardini, C., 2006. Blockade of intracellular calcium release induces an antidepressant-like effect in the mouse forced swimming test. Neuropharmacology. 50, 309-316.

Huntington, N.D., Tomioka, R., Clavarino, C., Chow, A.M., Linares, D., Mana, P., Rossjohn, J., Cachero, T.G., Qian, F., Kalled, S.L., Bernard, C.C., Reid, H.H., 2006. A BAFF antagonist suppresses experimental autoimmune encephalomyelitis by targeting cell-mediated and humoral immune responses. Int. Immunol. 18, 1473-1485.

Ichikawa, M., Koh, C.S., Inoue, A., Tsuyusaki, J., Yamazaki, M., Inaba, Y., Sekiguchi, Y., Itoh, M., Yagita, H., Komiyama, A., 2000. Anti-IL-12 antibody prevents the development and progression of multiple sclerosis-like relapsing-remitting demyelinating disease in NOD mice induced with myelin oligodendrocyte glycoprotein peptide. J. Neuroimmunol. 102, 56-66.

Jayaraman, A., Soni, A., Prabhakar, B.S., Holterman, M., Jayaraman, S., 2017. The epigenetic drug Trichostatin a ameliorates experimental autoimmune encephalomyelitis via $\mathrm{T}$ cell tolerance induction and impaired influx of $\mathrm{T}$ cells into the spinal cord. Neurobiol. Dis. 108 (1-12).

Kappos, L., Bar-Or, A., Cree, B.A.C., Fox, R.J., Giovannoni, G., Gold, R., Vermersch, P., Arnold, D.L., Arnould, S., Scherz, T., Wolf, C., Wallstrom, E., Dahlke, F., 2018. Siponimod versus placebo in secondary progressive multiple sclerosis (EXPAND): a double-blind, randomised, phase 3 study. Lancet. 391, 1263-1273.

Komen, J.C., Thorburn, D.R., 2014. Turn up the power - pharmacological activation of mitochondrial biogenesis in mouse models. Br. J. Pharmacol. 171, 1818-1836.

Lassmann, H., 2018. Pathogenic mechanisms associated with different clinical courses of multiple sclerosis. Front. Immunol. 9, 3116.

Lassmann, H., Bradl, M., 2017. Multiple sclerosis: experimental models and reality. Acta Neuropathol. 133, 223-244.

Lee, J.Y., Taghian, K., Petratos, S., 2014. Axonal degeneration in multiple sclerosis: can we predict and prevent permanent disability? Acta Neuropathol. Commun. 2, 97.

Liu, G., Muili, K.A., Agache, V.V., Lyons, J.A., 2012. Unique B cell responses in B celldependent and B cell-independent EAE. Autoimmunity. 45, 199-209.

Matute, C., Alberdi, E., Domercq, M., Perez-Cerda, F., Perez-Samartin, A., SanchezGomez, M.V., 2001. The link between excitotoxic oligodendroglial death and demyelinating diseases. Trends Neurosci. 24, 224-230.

Mayo, L., Cunha, A.P., Madi, A., Beynon, V., Yang, Z., Alvarez, J.I., Prat, A., Sobel, R.A., Kobzik, L., Lassmann, H., Quintana, F.J., Weiner, H.L., 2016. IL-10-dependent Tr1 cells attenuate astrocyte activation and ameliorate chronic central nervous system inflammation. Brain. 139, 1939-1957.

McMahon, E.J., Bailey, S.L., Castenada, C.V., Waldner, H., Miller, S.D., 2005. Epitope spreading initiates in the CNS in two mouse models of multiple sclerosis. Nat.Med. $11,335-339$.

Milligan, N.M., Newcombe, R., Compston, D.A., 1987. A double-blind controlled trial of high dose methylprednisolone in patients with multiple sclerosis: 1 . Clinical effects. J. Neurol. Neurosurg. Psychiatry 50, 511-516.

Montalban, X., Hauser, S.L., Kappos, L., Arnold, D.L., Bar-Or, A., Comi, G., De Seze, J., Giovannoni, G., Hartung, H.P., Hemmer, B., Lublin, F., Rammohan, K.W., Selmaj, K., Traboulsee, A., Sauter, A., Masterman, D., Fontoura, P., Belachew, S., Garren, H., Mairon, N., Chin, P., Wolinsky, J.S., 2017. Ocrelizumab versus placebo in primary progressive multiple sclerosis. N. Engl. J. Med. 376, 209-220.

Noe, N., Dillon, L., Lellek, V., Diaz, F., Hida, A., Moraes, C.T., Wenz, T., 2013. Bezafibrate improves mitochondrial function in the CNS of a mouse model of mitochondrial encephalopathy. Mitochondrion. 13, 417-426.
Ochoa-Ruiz, E., Diaz-Ruiz, R., Hernandez-Vazquez, A.J., Ibarra-Gonzalez, I., Ortiz-Plata, A., Rembao, D., Ortega-Cuellar, D., Viollet, B., Uribe-Carvajal, S., Corella, J.A., Velazquez-Arellano, A., 2015. Biotin deprivation impairs mitochondrial structure and function and has implications for inherited metabolic disorders. Mol. Genet. Metab. 116, 204-214.

Ontaneda, D., Fox, R.J., 2015. Progressive multiple sclerosis. Curr. Opin. Neurol. 28, 237-243.

Perkins, G.A., Ellisman, M.H., 2011. Mitochondrial configurations in peripheral nerve suggest differential ATP production. J. Struct. Biol. 173, 117-127.

Peterson, J.W., Bo, L., Mork, S., Chang, A., Trapp, B.D., 2001. Transected neurites, apoptotic neurons, and reduced inflammation in cortical multiple sclerosis lesions. Ann. Neurol. 50, 389-400.

Pitt, D., Werner, P., Rainer, C.S., 2000. Glutamate excititoxicity in a model of multiple sclerosis. Nat. Med. 6, 67-70.

Quintana, F.J., Patel, B., Yeste, A., Nyirenda, M., Kenison, J., Rahbari, R., Fetco, D., Hussain, M., O'Mahony, J., Magalhaes, S., McGowan, M., Johnson, T., Rajasekharan, S., Narayanan, S., Arnold, D.L., Weiner, H.L., Banwell, B., Bar-Or, A., 2014. Epitope spreading as an early pathogenic event in pediatric multiple sclerosis. Neurology. 83, 2219-2226.

Riveron-Negrete, L., Fernandez-Mejia, C., 2017. Pharmacological effects of biotin in animals. Mini-Rev. Med. Chem. 17, 529-540.

Sadelain, M.W., Qin, H.Y., Lauzon, J., Singh, B., 1990. Prevention of type I diabetes in NOD mice by adjuvant immunotherapy. Diabetes. 39, 583-589.

Sedel, F., Bernard, D., Mock, D.M., Tourbah, A., 2016. Targeting demyelination and virtual hypoxia with high-dose biotin as a treatment for progressive multiple sclerosis. Neuropharmacology. 110, 644-653.

Tong, L., 2013. Structure and function of biotin-dependent carboxylases. Cell. Mol. Life Sci. 70, 863-891.

Tourbah, A., Gout, O., Vighetto, A., Deburghgraeve, V., Pelletier, J., Papeix, C., LebrunFrenay, C., Labauge, P., Brassat, D., Toosy, A., Laplaud, D.A., Outteryck, O., Moreau, T., Debouverie, M., Clavelou, P., Heinzlef, O., De Seze, J., Defer, G., Sedel, F., Arndt, C., 2018. MD1003 (high-dose pharmaceutical-grade biotin) for the treatment of chronic visual loss related to optic neuritis in multiple sclerosis: a randomized, double-blind, placebo-controlled study. CNS.Drugs. 32, 661-672.

Trapp, B.D., Stys, P.K., 2009. Virtual hypoxia and chronic necrosis of demyelinated axons in multiple sclerosis. Lancet Neurol. 8, 280-291.

Trapp, B.D., Peterson, J., Ransohoff, R.M., Rudick, R., Mork, S., Bo, L., 1998. Axonal transection in the lesions of multiple sclerosis. N. Engl. J. Med. 338, 278-285.

Vercellino, M., Plano, F., Votta, B., Mutani, R., Giordana, M.T., Cavalla, P., 2005. Grey matter pathology in multiple sclerosis. J. Neuropathol. Exp. Neurol. 64, 1101-1107.

Wang, H., Zhou, J., Liu, Q.Z., Wang, L.L., Shang, J., 2017. Simvastatin and Bezafibrate ameliorate emotional disorder induced by high fat diet in C57BL/6 mice. Sci. Rep. 7, 2335 .

Wegner, C., Esiri, M.M., Chance, S.A., Palace, J., Matthews, P.M., 2006. Neocortical neuronal, synaptic, and glial loss in multiple sclerosis. Neurology. 67, 960-967.

Winer, S., Astsaturov, I., Cheung, R., Gunaratnam, L., Kubiak, V., Cortez, M.A., Moscarello, M., O'Connor, P.W., McKerlie, C., Becker, D.J., Dosch, H.M., 2001. Type I diabetes and multiple sclerosis patients target islet plus central nervous system autoantigens; nonimmunized nonobese diabetic mice can develop autoimmune encephalitis. J. Immunol. 166, 2831-2841.

Witte, M.E., Mahad, D.J., Lassmann, H., van Horssen, J., 2013a. Mitochondrial dysfunction contributes to neurodegeneration in multiple sclerosis. Trends Mol. Med. 20, 179-187.

Witte, M.E., Nijland, P.G., Drexhage, J.A., Gerritsen, W., Geerts, D., van Het, H.B., Reijerkerk, A., de Vries, H.E., van, d., Vvan Horssen, J., 2013b. Reduced expression of PGC-1alpha partly underlies mitochondrial changes and correlates with neuronal loss in multiple sclerosis cortex. Acta Neuropathol. 125, 231-243.

Witte, M.E., Schumacher, A.M., Mahler, C.F., Bewersdorf, J.P., Lehmitz, J., Scheiter, A., Sanchez, P., Williams, P.R., Griesbeck, O., Naumann, R., Misgeld, T., Kerschensteiner, M., 2019. Calcium influx through plasma-membrane nanoruptures drives axon degeneration in a model of multiple sclerosis. Neuron. 101, 615-624.

Wüst, S., van den Brandt, J., Tischner, D., Kleiman, A., Tuckermann, J.P., Gold, R., Lühder, F., Reichardt, H.M., 2008. Peripheral T cells are the therapeutic targets of glucocorticoids in experimental autoimmune encephalomyelitis. J. Immunol. 180, 8434-8443. 